\title{
Tuning Coordination Modes and Nucleation of Calcium Phosphate with Oligomeric Lactic Acid and pH Values: Theoretical and Experimental Study
}

Hongwei Chen, ${ }^{\# 1}$ Changchang Lv, ${ }^{\# 1}$ Lin Guo, ${ }^{* 1}$ Ming Ma, ${ }^{2}$ Zhengyi Lan, ${ }^{2}$ Jun Huo, ${ }^{3}$ Hao Dong, ${ }^{3}$ Xiangdong Zhu, ${ }^{4}$ Qiang Zhu, ${ }^{1}$ Yuming $G u,{ }^{1}$ Ziteng Liu, ${ }^{1}$ Jianjun Liu, ${ }^{2}$ Hangrong Chen, ${ }^{2}$ Xuefeng Guo, ${ }^{* 1}$ Jing Ma, *1

${ }^{1}$ Key Laboratory of Mesoscopic Chemistry of Ministry of Education, School of Chemistry and Chemical Engineering, Nanjing University, Nanjing, 210023, P. R. China

${ }^{2}$ Shanghai Institute of Ceramics, Chinese Academy of Sciences, 200050, Shanghai, China

${ }^{3}$ Kuang Yaming Honors School \& Institute for Brain Sciences, Nanjing University, Nanjing 210023, China

${ }^{4}$ National Engineering Research Center for Biomaterials, Sichuan University, Chengdu, 610064, China.

\# These two authors contributed equally to this work.

*Address correspondence to majing@,nju.edu.cn (Prof. J. Ma); linguo@nju.edu.cn (Prof. L. Guo); guoxf@nju.edu.cn (Prof. X. Guo)

KEYWORDS: Nucleation, calcium phosphate, Lactic acid, pH, SBF solution, High-throughput experimentations 
ABSTRACT: Mineralization of calcium phosphate $(\mathrm{CaP})$ is ubiquitous in nature, which can facilitate biological organisms produce hierarchically structured minerals. The influences of the addition of oligomeric lactic acid $\left(\mathrm{LAC}_{\mathrm{n}}, \mathrm{n}=1,8\right)$ and changing $\mathrm{pH}$ values on nucleation processes of $\mathrm{CaP}$ under the simulated body fluid (SBF) solution or aqueous solution were revealed by using ab initio molecular dynamics (AIMD) and molecular dynamics (MD) simulations. Through increasing $\mathrm{pH}$ value, the coordination between differently protonated phosphate species and $\mathrm{Ca}^{2+}$ ions could be tuned from the monodentate $\left(\eta^{1}\right)$ to the coexisting monodentate and bidentate $\left(\eta^{2}\right)$ modes. The carboxyl and hydroxyl groups of LAC molecules are capable of forming multiple interactions such as proton transfer, electrostatic interaction, and intermolecular hydrogen bonding with phosphate species and $\mathrm{Ca}^{2+}$ ions on both prenucleation clusters and hydroxyapatite (HA) surfaces. The high-throughput experimentations (HTE) with factors of the adding LAC, changing $\mathrm{Ca} / \mathrm{P}$ ratios $(1.25$ 2.50), using different solutions demonstrated that the UV-Vis absorbance values decreased with addition of LAC, indicating the inhibition of the nucleation process of $\mathrm{CaP}$. At the physiological $\mathrm{pH}$ of 7.4 , the $\mathrm{CaP}$ samples with different $\mathrm{Ca} / \mathrm{P}$ ratios $(1.50$, 1.67 and 2.00) exhibited negative zeta potential values, which were correlated with the surface electrostatic potential distributions and potential biological applications. The precipitation was $\mathrm{CaHPO}_{4} \cdot 2 \mathrm{H}_{2} \mathrm{O}$ (DCPD) in neutral condition at the early stage of nucleation process. Understanding the effects of different $\mathrm{pH}$ and $\mathrm{Ca} / \mathrm{P}$ values on the nucleation process and interfacial interaction between LAC additive and the nanocluster is helpful to guide the rational design of biocompatible materials. 


\section{Introduction}

Mineralization, which is an important biological process, facilitates biological organisms produce hierarchically structured minerals. Bones and teeth of vertebrates are known to come from CaP minerals, ${ }^{1}$ whose nucleation process was proposed to have two possibilities, i.e., a classical aggregation or a two-step nucleation pathway. ${ }^{2}$ In the classical viewpoint, the ions of solution could directly aggregate, nucleation, and finally crystallization. Another two-step nucleation pathway proposal indicated that the ions could self-assemble to form metastable amorphous clusters, and then aggregated together to fulfill final precipitation in solution. In fact, the real nucleation process of $\mathrm{CaP}$ in biological condition should be much more complicated because many factors such as adding additive, $\mathrm{Ca} / \mathrm{P}$ ratio, carbonate ions and $\mathrm{pH}$ value could affect the occurrence of different phosphate species such as $\mathrm{H}_{3} \mathrm{PO}_{4}$ (called $3 \mathrm{H}$ for short), $\mathrm{H}_{2} \mathrm{PO}_{4}{ }^{-}$ $(2 \mathrm{H}), \mathrm{HPO}_{4}{ }^{2-}(1 \mathrm{H})$, and $\mathrm{PO}_{4}{ }^{3-}(\mathrm{OH})$, shown in Figure 1a. It is known that in the CaP solution, starting from the ion pair $\mathrm{CaHPO}_{4}$, pre-nucleation cluster $\mathrm{Ca}\left(\mathrm{HPO}_{4}\right)_{3}{ }^{4-}$ could be gradually formed at the early stages nucleation process. ${ }^{3-6}$ Such a CaP cluster $\left[\mathrm{Ca}\left(\mathrm{HPO}_{4}\right)_{3}\right]^{4-}$ was demonstrated to exist both $\eta^{1}$ and $\eta^{1}$ modes, i.e., $\mathrm{Ca}\left(\eta^{2}-\mathrm{HPO}_{4}{ }^{2-}\right)_{2}\left(\eta^{1-}\right.$ $\left.\mathrm{HPO}_{4}{ }^{2-}\right)\left(\mathrm{H}_{2} \mathrm{O}\right)_{2}$ by using AIMD simulations with PBE functional. ${ }^{4}$ Subsequently, those small-sized clusters could aggregate into thermodynamically metastable amorphous $\mathrm{CaP}(\mathrm{ACP}) .^{7}$ The building blocks of ACP are further propagated with several nucleation mechanisms, such as post-nucleation cluster $\mathrm{Ca}_{2}\left(\mathrm{HPO}_{4}\right)_{3}{ }^{2-}$ and Posner's cluster $\mathrm{Ca} 9\left(\mathrm{PO}_{4}\right)_{6} \cdot{ }^{3,7-9}$ With the increase in cluster size, the ACP phase has been formed gradually as the precursor, and then transformed into octocalcium phosphate (OCP, $\left.\mathrm{Ca} 8\left(\mathrm{HPO}_{4}\right)_{2}\left(\mathrm{PO}_{4}\right)_{4} \cdot 5 \mathrm{H}_{2} \mathrm{O}\right)$ and crystalline phase. ${ }^{3,7} \mathrm{CaP}$ minerals in aqueous solution mainly include dicalcium phosphate dehydrate $\left(\mathrm{DCPD}, \mathrm{CaHPO}_{4} \cdot 2 \mathrm{H}_{2} \mathrm{O}\right)$, monocalcium phosphate monohydrate (MCPM, $\mathrm{Ca}\left(\mathrm{H}_{2} \mathrm{PO}_{4}\right)_{2} \cdot \mathrm{H}_{2} \mathrm{O}$ ), OCP and hydroxyapatite (HA, $\left.\mathrm{Ca}_{10}\left(\mathrm{PO}_{4}\right)_{6}(\mathrm{OH})_{2}\right) .{ }^{10}$ Among them, HA is considered the most thermodynamically stable phase of $\mathrm{CaP}$ minerals. It has received much attention as a potential anti-tumor material due to the ability of inhibiting the proliferation of various tumor cells. ${ }^{11-16}$ 
(a)

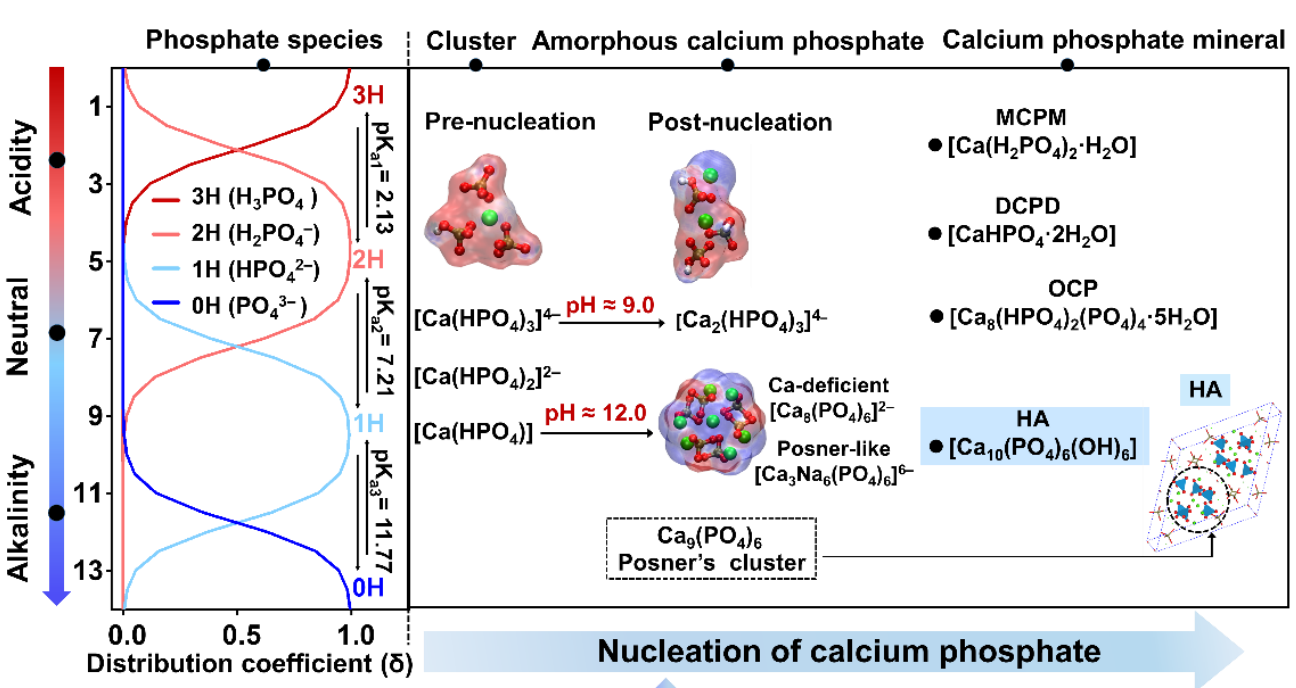

(b)

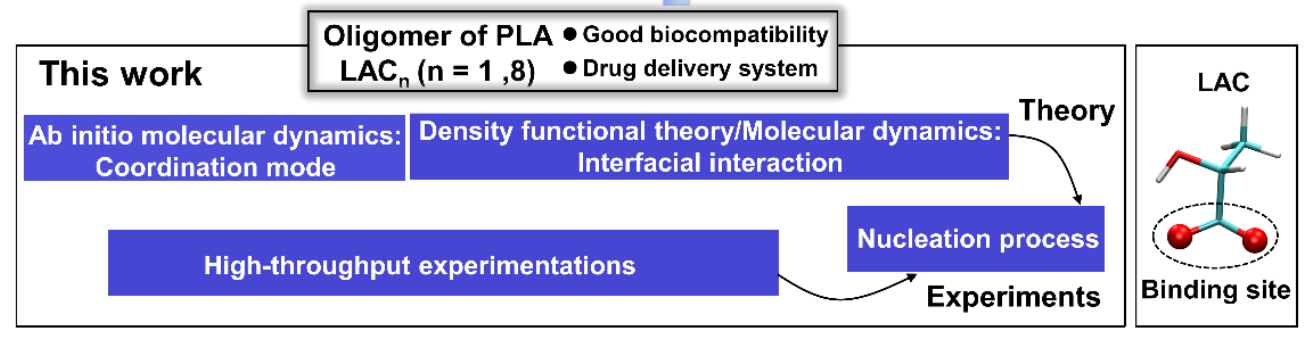

Figure 1. (a) The distribution coefficient $\delta$ of phosphate species, $\mathrm{H}_{3} \mathrm{PO}_{4}(3 \mathrm{H}), \mathrm{H}_{2} \mathrm{PO}_{4}^{-}$ $(2 \mathrm{H}), \mathrm{HPO}_{4}{ }^{2-}(1 \mathrm{H})$, and $\mathrm{PO}_{4}{ }^{3-}(0 \mathrm{H})$, as a function of $\mathrm{pH}$ values, and the schematic illustration of nucleation process of $\mathrm{CaP}$, (b) The influence of $\mathrm{LAC}_{\mathrm{n}}(\mathrm{n}=1,8)$ additives and $\mathrm{pH}$ values on the nucleation is investigated in this work through theoretical (AIMD, DFT, and MD) and experimental (UV-Vis, XRD, TEM, and Zeta potential) study.

The sequential nucleation and crystal growth processes in biomineralization have aroused intensive interest in both experimental and theoretical studies. Scanning electron microscopy (SEM) and XRD experiments indicated that the nucleation and growth of HA were promoted on some substrates, such as chitosan-coated polylactic acid (PLA) nanofiber, polylactide/gelatin composite nanofibers, lignin/polycaprolactone nanofibers and polydopamine, ${ }^{17-25}$ due to chelation of the coated hydroxyl or carboxylate groups with $\mathrm{Ca}^{2+}$ ions in the simulated body fluid (SBF, whose ion concentrations and $\mathrm{pH}$ value are similar to the human blood plasma). It has also been found that the $\mathrm{pH}$ condition has great influence on the intrinsic 
physicochemical characteristics of various $\mathrm{CaP}$ samples, including adsorption of organic acids ${ }^{26}$, phase composition ${ }^{27}$, morphology and crystal size ${ }^{28}$. Moreover, zeta potentials were affected by $\mathrm{pH}$ values for many nanoparticles, such as iron oxide nanoparticles, ${ }^{29} \mathrm{Ag} @ \mathrm{HA},{ }^{30} \mathrm{~F}-\mathrm{Cl} @ \mathrm{HA},{ }^{31}$ and the complexes of HA with the additives of citric acid ${ }^{32}$, oxalic acid ${ }^{33}$ and malic acid ${ }^{34}$. Such negative zeta potentials of nanoparticles were proposed to favor osseointegration, apatite nucleation, and inhibition of tumor cell proliferation. ${ }^{14,29,31,35,36}$

Some experimental phenomena have been rationalized by molecular dynamics simulations. For example, the addition of substrate such as cellulose nanofibrils ${ }^{37}$ is less favorable for the formation of $\mathrm{CaP}$ clusters than those in solutions based on $\mathrm{MD}$ simulations with CSFF force field. The surface of protein is dominated by amino acid residues, which could provide adequate reactive sites to bind with $\mathrm{Ca}^{2+}$ or phosphate ions through electrostatic interaction or hydrogen bonding and facilitate the nucleation and growth of $\mathrm{CaP}$. The regulation of nucleation process of $\mathrm{CaP}$ by the charged amino acids of collagen surface was demonstrated by CHARMM27 based MD study in solution. ${ }^{38-40}$ Neutral amino acids of collagen such as glycine and hydroxyproline residues, whose carboxylate groups were also found to be freely accessible to the $\mathrm{Ca}^{2+}$ ions based on generalized AMBER force field. ${ }^{41}$ The interactions between lysine and HA (100) surface was ascribed to the dominant electrostatic interaction in $\mathrm{Ca}-\mathrm{O}$ ionic bonding, followed by hydrogen bonding between $\mathrm{C}_{\varepsilon}$-H/amine- $\mathrm{H}$ and phosphate-O ${ }^{42}$ Electrostatic interactions were also found to play an important role in binding of $\mathrm{CaP}$ clusters with proteins such as bone morphological protein- $2^{43}$ and clathrin-associated protein adaptin-2 (AP2) ${ }^{44}$ especially with the charged residues. The important role of hydrogen bonding interaction in the nucleation of $\mathrm{CaP}$ was revealed by oxygen plasma treatment and MD simulations with GAFF force field, from which $\mathrm{H}_{2} \mathrm{PO}_{4}^{-}$ions were shown to be initially adsorbed at the $-\mathrm{OH}$-modified parylene $\mathrm{C}$ surface accompanied by $\mathrm{Ca}^{2+}$ and $\mathrm{HPO}_{4}{ }^{2-}$ ions. ${ }^{45}$ 
(a)

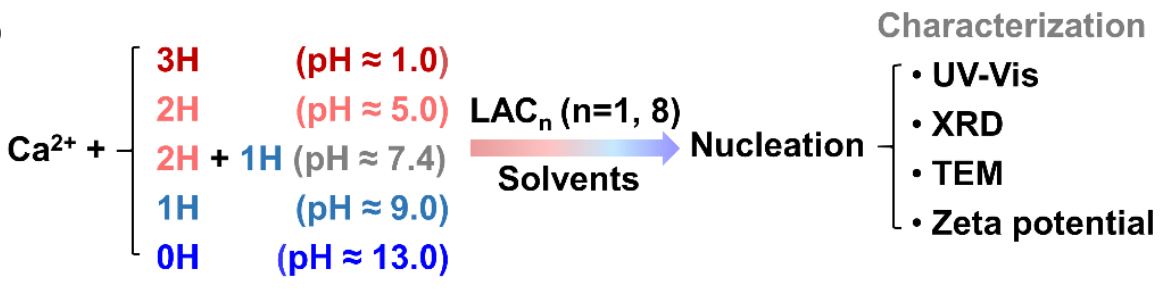

(b) Molecular simulations: MD and AIMD

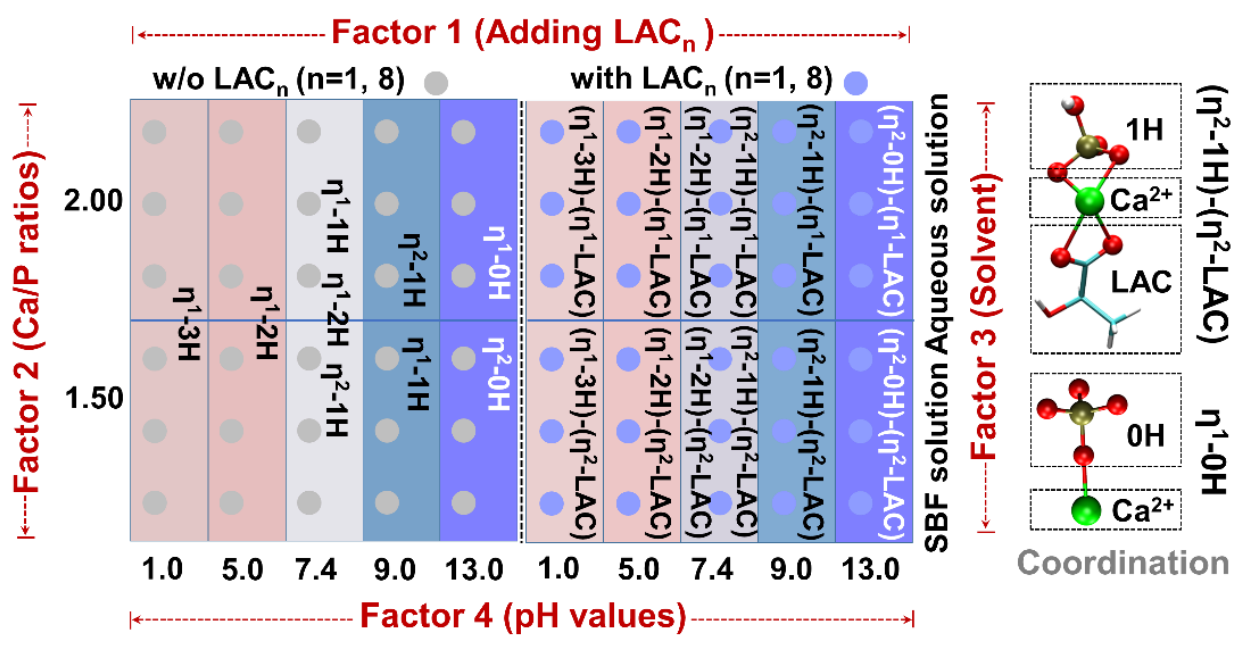

(c) High-throughput experimentations

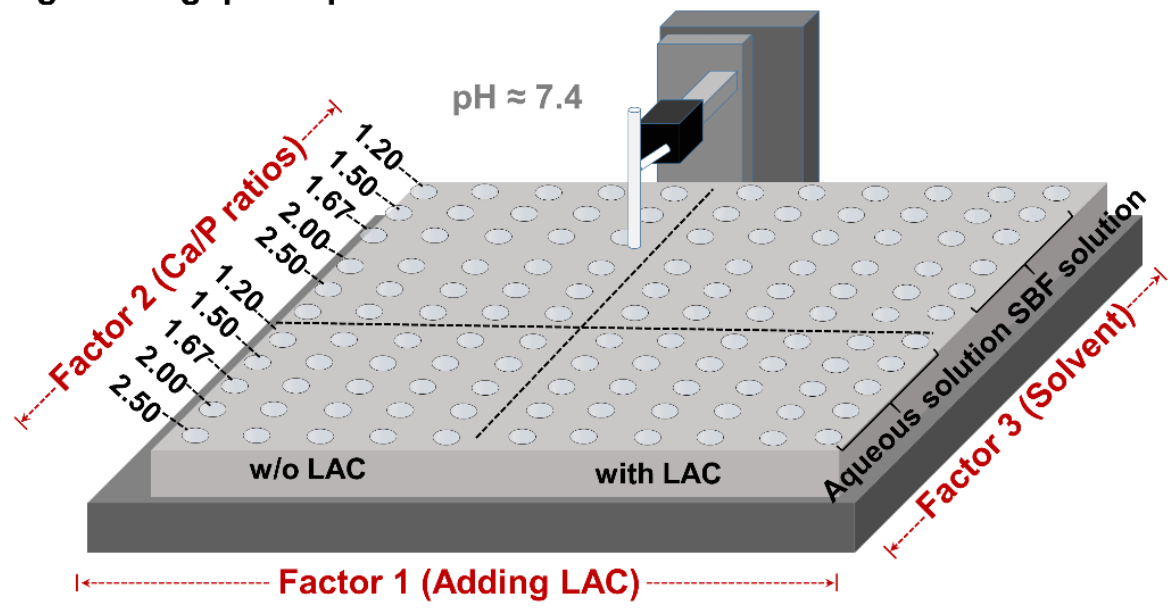

Figure 2. (a) The model build and experimental detection methods in studied systems, (b) the main factors affecting the nucleation of $\mathrm{CaP}$, (c) schematic diagram of highthroughput experimentations equipment.

In the present work, we are interested in the interaction of the oxygen-containg molecules, such as LAC, with CaP systems, since LAC is the basic block of PLA, which is one of the widely used biodegradable polyesters in medical applications. ${ }^{46}$ Lactic acid 
is also a by-product of aerobic or anaerobic glycolysis, and its high amount is a characteristic feature of tumor cells. ${ }^{47}$ It could function as a key signaling molecule in detecting cancer cell migration, angiogenesis and metastasis. ${ }^{48}$ Taking into account the value of lactic acid dissociation constant of $\mathrm{pK}_{\mathrm{a}}=3.86,{ }^{49}$ the deprotonated lactic acid form (also called LAC for short) is the dominated species in the studied $\mathrm{pH}$ conditions except for the simulation with $\mathrm{pH}=1.0$ (Figure 1). The nucleation process of $\mathrm{CaP}$ based on the four factors (adding $\mathrm{LAC}_{\mathrm{n}}(\mathrm{n}=1,8), \mathrm{Ca} / \mathrm{P}$ ratio, $\mathrm{pH}$ value, and $\mathrm{SBF} /$ aqueous solution) (Figure 1b) was systematically investigated by using AIMD and MD simulations as well as high-throughput experimentations (HTE). Density functional theory (DFT) was employed to depict the coordination modes and their binding strength between $\mathrm{Ca}^{2+}$ ions and phosphate species with and without the addition of LAC oligomers. AIMD and MD simulations demonstrated the aggregation processes of CaP clusters in both SBF and aqueous solutions. HTE ${ }^{50}$ allowed a large number of experiments about changing the $\mathrm{Ca} / \mathrm{P}$ ratios, additives, and solvents to be executed in parallel (Figure 2). An in-depth atomistic insight into the nucleation process of CaP under different values of $\mathrm{pH}$ and $\mathrm{Ca} / \mathrm{P}$ ratios with the addition of LAC is important to comprehend the influence of various factors on the binding modes and to guide the rational design of potential biomaterials.

\section{Materials and Methods}

\subsection{Binding strength estimated by DFT calculations.}

To study the influence of $\mathrm{pH}$ values and the addition of LAC on interfacial interactions of $\mathrm{CaP}$ with the surrounding species, the binding strength of $\mathrm{Ca}^{2+}(\mathrm{M})$ with the ligand (Y), including phosphate species, carbonate species $\left(\mathrm{H}_{2} \mathrm{CO}_{3}, \mathrm{HCO}_{3}{ }^{-}, \mathrm{CO}_{3}{ }^{2-}\right)$ in the simulated body fluid, LAC oligomers, and solvent molecules (water or $\mathrm{CH}_{3} \mathrm{COOH}$ ), was calculated by using density functional theory (DFT) with the implicit polarizable continuum model (PCM) at the level of DFT/M062X/6-311+g(d,p) within 
the Gaussian 16 package $^{51}$. The binding free energy, $\mathrm{G}_{\text {bind, }}$, of a CaP cluster in a certain $\mathrm{pH}$ condition was derived from the following equation,

$$
\mathrm{G}_{\mathrm{bind}}=\mathrm{G}_{\mathrm{MY}}+6 \times \mathrm{G}_{\mathrm{wt}}-\mathrm{G}_{\mathrm{Y}}-\mathrm{G}_{\mathrm{M}(\mathrm{wt})_{6}}
$$

where $\mathrm{M}=\mathrm{Ca}^{2+}$, whose 6 -coordinated complexation with water (wt), $\mathrm{M}(\mathrm{wt})_{6}{ }^{2+}$, is taken as a reference in binding Gibbs free energy $(\mathrm{G})$ calculations. The optimized geometries of the studied systems are presented in Figure S1 and the calculated Gibbs free energies at $298 \mathrm{~K}$ are listed in Table S1. A negative value of $\mathrm{G}_{\mathrm{bind}}$ of a complex indicates that this compound is thermodynamically more stable than the $\mathrm{Ca}(\mathrm{wt}) 6^{2+}$ complex, causing the competitive interaction with $\mathrm{Ca}^{2+}$ ions in the presence of various additives.

With an increase in the cluster size, crystallization may take place after some treatments. The two-layer slab model with periodic boundary condition (PBC) was applied to simulate the binding of LAC on the HA surface using the DFT calculations with the plane wave-based Vienna ab initio simulation package (VASP) ${ }^{52}$. The details of slab models were given in supporting information. DFT calculations were performed within generalized gradient approximation (GGA) with Perdew-Burke-Ernzerhof $(\mathrm{PBE})^{53}$ functional. The van de Walls (vdW) correction with the Grimme approach (DFT-D3) ${ }^{54}$ was performed to describe the interaction between the additive species and surfaces. The relative stabilities of two different surfaces, i.e., (001) versus (100) of HA

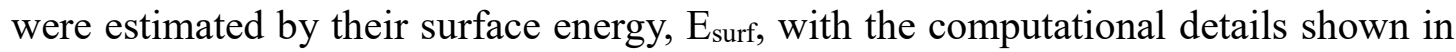
supporting information. To estimate the interaction energy between LAC and HA slab with different $\mathrm{Ca} / \mathrm{P}$ ratios (Figure S2 and Figure S3), the binding energies ( $\mathrm{E}_{\text {bind }}$ ) were calculated from the energy difference between the whole system and the individual components, as shown in Table S2. To correlate the binding strength with the extent of interfacial charge transfer, the atomic charges were evaluated by Bader charge analysis $^{55}$.

2.2. MD simulations of aggregation and nucleation of $\mathrm{CaP}$. To study the nucleation process of $\mathrm{CaP}$ in $\mathrm{SBF}$ solution w/o or with oligomeric $\mathrm{LAC}_{\mathrm{n}}(\mathrm{n}=1,8)$ additives, we carried out the MD simulations by using AMBER16 CUDA version ${ }^{56}$. The octamer 
$\mathrm{LAC}_{8}$ was taken as an example to model the interfacial interaction of polylactic acid (PLA) polymer with the CaP clusters. The $\mathrm{pK}_{\mathrm{a}}$ of LAC and oligomeric PLA are 3.86 and 3.10, ${ }^{49,57}$ respectively. When the $\mathrm{pH}$ is greater than 5, they are both in deprotonated states (Figure S4). In addition, there are several kinds of anions in SBF solution, such as carbonate ions, whose protonation state distribution at different $\mathrm{pH}$ values depends on their $\mathrm{pK}_{\mathrm{a}}$ values ${ }^{58-60}$, as shown in Figure S5. The GAFF2 force field was used for the phosphate species, with the force field parameters shown in Table S3. The 500 ns MD simulations were run at NPT ensemble (with the constant pressure of 1.0 bar and temperature of $300 \mathrm{~K}$ ) for the model systems with different $\mathrm{pH}$ values and $\mathrm{Ca} / \mathrm{P}$ ratios, as shown in Tables S4-S9. The temperature was controlled using Langevin dynamics ${ }^{61}$ with the collision frequency of $1 \mathrm{ps}^{-1}$. Integration step at $1 \mathrm{fs}$ was set and the direct spatial nonbonded cutoff of $8.0 \AA$ was used. The local binding modes were displayed from the radial distribution function (RDF) and spatial distribution function (SDF) using VMD $^{8}$ and TRAVIS ${ }^{9}$ programs, respectively. Adaptive Poisson-Boltzmann Solver (APBS) ${ }^{62}$ was employed to study the electrostatic properties of the CaP clusters. 2.3. AIMD simulations for exploring the local coordination modes. In order to provide the more detailed information of the intermolecular interaction in the early aggregation stage, the AIMD simulations were carried out using $\mathrm{CP} 2 \mathrm{~K}$ with $\mathrm{PBE}$ functional and GTH-DZVP basis set ${ }^{63,64}$ for all atoms. The Grimme algorithm (DFTD3 $)^{54}$ was employed to improve the description of van der Waals (vdW) interactions. The energy cutoff for plane wave basis set was $550 \mathrm{Ry}$. Several CaP systems with different protonation conditions (Table S10) with or without the addition of LAC were set by using the Packmol code ${ }^{65}$ in a PBC cell of $14 \times 14 \times 14 \AA^{3}$ to illustrate the coordination modes between different phosphate species and $\mathrm{Ca}^{2+}$ ions under different $\mathrm{pH}$ values. The counterions, $\mathrm{Na}^{+}$or $\mathrm{Cl}^{-}$ions, were added to neutralize the excess charge. The 20 ps AIMD trajectory was generated in an NPT ensemble at $300 \mathrm{~K}$ and 1 bar with a time step of $0.5 \mathrm{fs}$.

2.5. High-throughput experimentation (HTE) for tuning various factors. The highthroughput experimentations were carried out using the house-made synthesis 
equipment (Figure 2c and Figure S6). Based on combinatoric chemistry method, we developed a high-through microarray synthesis equipment which is composed of a multi-channel sample collection platform, a multi-channel automatic liquid injection system and an automatic stirring system. The addition of reaction solution, the stirring speed and the stepping of XY-axis motion guide can be controlled by the computer with our self-compiled operating software. Therefore, the input ratio of different reactants, the $\mathrm{pH}$ value of solution, reaction temperature and stirring time can be auto-executed by preset system. Through this equipment, different samples can be automatically synthesized one by one.

Calcium chloride $\left(\mathrm{CaCl}_{2} \cdot 2 \mathrm{H}_{2} \mathrm{O}\right)$ and diammonium hydrogen phosphate $\left(\left(\mathrm{NH}_{4}\right)_{2} \mathrm{HPO}_{4}\right)$ were purchased from Sinopharm Chemical Reagent Co., Ltd. SBF solution was directly acquired from Shanghai Yuanye Bio-technology Co.,Ltd. The species of lactic acid (LAC) used as factor 1 in the $\mathrm{CaP}$ nucleation experiments was provided by Shanghai Aladdin Bio-Chem Technology Co., Ltd. To obtain enough precipitate for XRD and TEM characterizations, LAC (purity $\geq 95 \%$ ), $\mathrm{CaCl}_{2} \cdot 2 \mathrm{H}_{2} \mathrm{O}$, $\left(\mathrm{NH}_{4}\right)_{2} \mathrm{HPO}_{4}$, and SBF solution were purchased from Shanghai Bide Chemical Reagent Co,. Ltd., Shanghai Hushi Chemical Reagent Co., Ltd, and Phygene Life Sciences Co., Ltd., respectively. All chemicals were used without further purification.

For HTE, the concentration of $\left(\mathrm{NH}_{4}\right)_{2} \mathrm{HPO}_{4}$ was about 0.006700 and 0.003335 mol $\cdot \mathrm{dm}^{-3}$, and remained unchanged. The concentration of $\mathrm{CaCl}_{2}$ was determined by modifying the $\mathrm{Ca} / \mathrm{P}$ ratios of $1.25,150,1.67,2.00,2.50$ and 2.75 (factor 2), respectively. The solvents used in this HTE included aqueous solution and SBF solution (factor 3). Firstly, the prepared $\left(\mathrm{NH}_{4}\right)_{2} \mathrm{HPO}_{4}, \mathrm{CaCl}_{2}$ and $\mathrm{LAC}$ solutions (factor 1) were adjusted to pH about 7.4 with $\mathrm{NH}_{3} \cdot \mathrm{H}_{2} \mathrm{O}$ or $\mathrm{HCl}$. The above neutral solutions were mixed together in the order of $\mathrm{LAC},\left(\mathrm{NH}_{4}\right)_{2} \mathrm{HPO}_{4}$ and $\mathrm{CaCl}_{2}$ (Figure S6, Tables S11-S18). Then, the reactions were automatically carried out through the high-throughput material synthesis equipment and stirred for three minutes for each experimrnt group. For each $\mathrm{Ca} / \mathrm{P}$ ratio group, the experiments were repeated three times. Finally, the amounts of precipitation formed in the 120 samples were derived from UV-Vis absorbance at $450 \mathrm{~nm}$, using a 
Shimadzu UV-2600 spectrophotometer instrument using SBF or the distilled water as the reference sample.

Zeta potential analysis was performed at room temperature on Zetasizer (Nano-Z, Malvern, UK) based on dynamic light scattering theory. Powder X-ray diffraction (XRD) analysis for the crystalline structures of the as-prepared products were conducted on a Shimadzu XRD-6000 instrument with $\mathrm{Cu} K \alpha$ radiation $(\lambda=0.154 \mathrm{~nm})$ generated at $40 \mathrm{kV}$ and $30 \mathrm{~mA}$. Transmission electron microscopy (TEM) images were obtained on JEOL JEM-1011 instrument with an accelerating voltage of $120 \mathrm{kV}$ to analyze the morphological and structural features of the as-made samples.

\section{Results and Discussion}

\subsection{Protonation states of phosphate species under different $\mathrm{pH}$ values}

Under different $\mathrm{pH}$ conditions the phosphate has different protonation states, called $3 \mathrm{H}, 2 \mathrm{H}, 1 \mathrm{H}, 0 \mathrm{H}$, respectively, whose distribution coefficients could be derived from the following acid-base equations:

$$
\begin{array}{ll}
\mathrm{H}_{3} \mathrm{PO}_{4} \rightleftharpoons \mathrm{H}^{+}+\mathrm{H}_{2} \mathrm{PO}_{4}^{-} & \mathrm{pK}_{\mathrm{a} 1}=2.125 \\
\mathrm{H}_{2} \mathrm{PO}_{4}^{-} \rightleftharpoons \mathrm{H}^{+}+\mathrm{HPO}_{4}^{2-} & \mathrm{pK}_{\mathrm{a} 2}=7.208 \\
\mathrm{HPO}_{4}^{2-} \rightleftharpoons \mathrm{H}^{+}+\mathrm{PO}_{4}^{3-} & \mathrm{pK}_{\mathrm{a} 3}=11.770
\end{array}
$$

The $\mathrm{pK}_{\mathrm{a} 1}, \mathrm{pK}_{\mathrm{a} 2}$ and $\mathrm{pK}_{\mathrm{a} 3}$ in equations (2)-(4) are the acid dissociation constants of phosphate ${ }^{58}$. According to those $\mathrm{pK}_{\mathrm{a}}$ values, one could predict the distribution coefficient, $\delta$, of each protonation state at a certain $\mathrm{pH}$ value by using the following equations.

$$
\begin{aligned}
& \delta(3 \mathrm{H})=\frac{\left[\mathrm{H}^{+}\right]^{3}}{\left[\mathrm{H}^{+}\right]^{3}+\mathrm{K}_{\mathrm{a} 1}\left[\mathrm{H}^{+}\right]^{2}+\mathrm{K}_{\mathrm{a} 1} \mathrm{~K}_{\mathrm{a} 2}\left[\mathrm{H}^{+}\right]+\mathrm{K}_{\mathrm{a} 1} \mathrm{~K}_{\mathrm{a} 2} \mathrm{~K}_{\mathrm{a} 3}} \\
& \delta(2 \mathrm{H})=\frac{\mathrm{K}_{\mathrm{a} 1}\left[\mathrm{H}^{+}\right]^{2}}{\left[\mathrm{H}^{+}\right]^{3}+\mathrm{K}_{\mathrm{a} 1}\left[\mathrm{H}^{+}\right]^{2}+\mathrm{K}_{\mathrm{a} 1} \mathrm{~K}_{\mathrm{a} 2}\left[\mathrm{H}^{+}\right]+\mathrm{K}_{\mathrm{a} 1} \mathrm{~K}_{\mathrm{a} 2} \mathrm{~K}_{\mathrm{a} 3}} \\
& \delta(1 \mathrm{H})=\frac{\mathrm{K}_{\mathrm{a} 1} \mathrm{~K}_{\mathrm{a} 2}\left[\mathrm{H}^{+}\right]}{\left[\mathrm{H}^{+}\right]^{3}+\mathrm{K}_{\mathrm{a} 1}\left[\mathrm{H}^{+}\right]^{2}+\mathrm{K}_{\mathrm{a} 1} \mathrm{~K}_{\mathrm{a} 2}\left[\mathrm{H}^{+}\right]+\mathrm{K}_{\mathrm{a} 1} \mathrm{~K}_{\mathrm{a} 2} \mathrm{~K}_{\mathrm{a} 3}}
\end{aligned}
$$




$$
\delta(0 \mathrm{H})=\frac{\mathrm{K}_{\mathrm{a} 1} \mathrm{~K}_{\mathrm{a} 2} \mathrm{~K}_{\mathrm{a} 3}}{\left[\mathrm{H}^{+}\right]^{3}+\mathrm{K}_{\mathrm{a} 1}\left[\mathrm{H}^{+}\right]^{2}+\mathrm{K}_{\mathrm{a} 1} \mathrm{~K}_{\mathrm{a} 2}\left[\mathrm{H}^{+}\right]+\mathrm{K}_{\mathrm{a} 1} \mathrm{~K}_{\mathrm{a} 2} \mathrm{~K}_{\mathrm{a} 3}}
$$

Here, the $\left[\mathrm{H}^{+}\right]$represents the concentration of the $\mathrm{H}^{+}$in phosphate aqueous solution, which could be derived from the experimentally detected $\mathrm{pH}$ values. According to the above equations, the $\mathrm{pH}$ dependent coefficients of different protonation states, $3 \mathrm{H}, 2 \mathrm{H}$, $1 \mathrm{H}$ and $0 \mathrm{H}$, were plotted in Figure $1 \mathrm{a}$ and as well as in literatures ${ }^{34,66}$. It is clear that phosphate solution is a mixture of different protonation states under the certain $\mathrm{pH}$ condition. For example, each of $1 \mathrm{H}$ and $2 \mathrm{H}$ accounted for approximately half with the $\mathrm{pH} \approx 7.20$.

When those differently protonated phosphate species meet the $\mathrm{Ca}^{2+}$ ions, different kinds of minerals, ${ }^{10}$ such as TCP $\left(\mathrm{Ca}_{3}\left(\mathrm{PO}_{4}\right)_{2}\right)$, MCPM $\left(\mathrm{Ca}\left(\mathrm{H}_{2} \mathrm{PO}_{4}\right)_{2} \cdot \mathrm{H}_{2} \mathrm{O}\right)$, and DCPD $\left(\mathrm{CaHPO}_{4} \cdot 2 \mathrm{H}_{2} \mathrm{O}\right)$, would be formed (Figure $1 \mathrm{~b}$ ). The formation of those solid $\mathrm{CaP}$ preciptitations is controlled by the following solid-liquid equilibrium equations.

$$
\begin{array}{ll}
\mathrm{Ca}_{3}\left(\mathrm{PO}_{4}\right)_{2} \rightleftharpoons 3 \mathrm{Ca}^{2+}+2 \mathrm{PO}_{4}^{3-} & \mathrm{K}_{\mathrm{sp}}=2.20 \times 10^{-30} \\
\mathrm{CaHPO}_{4} \cdot 2 \mathrm{H}_{2} \mathrm{O} \rightleftharpoons \mathrm{Ca}^{2+}+\mathrm{HPO}_{4}^{2-}+2 \mathrm{H}_{2} \mathrm{O} & \mathrm{K}_{\mathrm{sp}}=2.19 \times 10^{-7} \\
\mathrm{Ca}\left(\mathrm{H}_{2} \mathrm{PO}_{4}\right)_{2} \cdot \mathrm{H}_{2} \mathrm{O} \rightleftharpoons \mathrm{Ca}^{2+}+2 \mathrm{H}_{2} \mathrm{PO}_{4}^{-}+\mathrm{H}_{2} \mathrm{O} & \mathrm{K}_{\mathrm{sp}}=1.00 \times 10^{-1.14}
\end{array}
$$

The $\mathrm{K}_{\mathrm{sp}}$ in equations (9)-(11) represents the solubility product ${ }^{67,68}$. It should be mentioned that the $\mathrm{pH}$ value also affects the above equations, since the concentration of 'free' dissociated phosphate species in equations (5)-(8) is also determined by the $\mathrm{pK}_{\mathrm{a}}$ and the $\mathrm{pH}$ values shown in equations (2)-(4). Accordingly, the concentration of 'free' unbound $\mathrm{Ca}^{2+}$ ions could be derived from the $\mathrm{K}_{\mathrm{sp}}$ values of phosphate species. Such a concentration is a useful parameter in designing an experiment: once the real concentration of $\mathrm{Ca}^{2+}$ ion exceeded this value, the $\mathrm{CaP}$ precipitation would immediately occur in solution. On the other hand, to obtain enough precipitate for X-ray diffraction (XRD) analysis, the concentration of $\mathrm{Ca}^{2+}$ ion should be much larger than this free $\mathrm{Ca}^{2+}$ concentration value. 


\subsection{Interfacial interactions of LAC with CaP clusters and HA surfaces}

Coordination of calcium ions with phosphates. The different phosphate protonation states have different binding capacities with $\mathrm{Ca}^{2+}$ ions, as shown in Figure $3 \mathrm{a}$ and Table S1. The M062X/6-311+g(d,p) binding free energies, $\mathrm{G}_{\mathrm{bind}}$, of the complexes of phosphate species with calcium ions gradually increased as the $\mathrm{pH}$ value increases, indicating that the exposed oxygen atoms of the deprotonated phosphate state with negative partial charges are more affinitive to the positively charged $\mathrm{Ca}^{2+}$ ions than the protonated ones. It could be seen from Figure $3 \mathrm{a}$ that the $\mathrm{Ca}\left(\eta^{2}-\mathrm{OH}\right)$ cluster had the largest binding free energy $(-47.56 \mathrm{kcal} / \mathrm{mol})$, demonstrating that the $\eta^{2}$ combination of $\mathrm{Ca}^{2+}$ ions with the fully deprotonated $0 \mathrm{H}$ in alkaline condition was the most favorable, followed by $\mathrm{Ca}\left(\eta^{1}-0 \mathrm{H}\right)$ and $\mathrm{Ca}\left(\eta^{2}-1 \mathrm{H}\right)$. For $0 \mathrm{H}$ and $1 \mathrm{H}$ species, the binding free energies with $\mathrm{Ca}^{2+}$ ions by $\eta^{2}$ mode were larger than those of the complexation in $\eta^{1}$ mode, which will be correlated with the charge transfer extent in the following subsection. In comparison with the complexation with $1 \mathrm{H}$, the binding with $2 \mathrm{H}$ protonation state had the smaller binding free energy, implying that $\mathrm{Ca}^{2+}$ ions were relatively more easily chelated with $1 \mathrm{H}$ instead of $2 \mathrm{H}$ in neutral condition. The compound $\mathrm{Ca}\left(\eta^{1}-3 \mathrm{H}\right)$ in acidic condition had the smallest binding free energy $(-6.15$ $\mathrm{kcal} / \mathrm{mol})$. To sum up, the increase of $\mathrm{pH}$ value enhanced the electrostatic interaction between $\mathrm{Ca}^{2+}$ ions and the increased number of the exposed oxygen atoms of the deprotonated phosphate species. The increase of $\mathrm{pH}$ value was also found to enhance the interaction (solvation free energy) between phosphate species and water molecules by using the thermodynamic cycle at the COSMO/PBE/DNP level. ${ }^{69}$ 


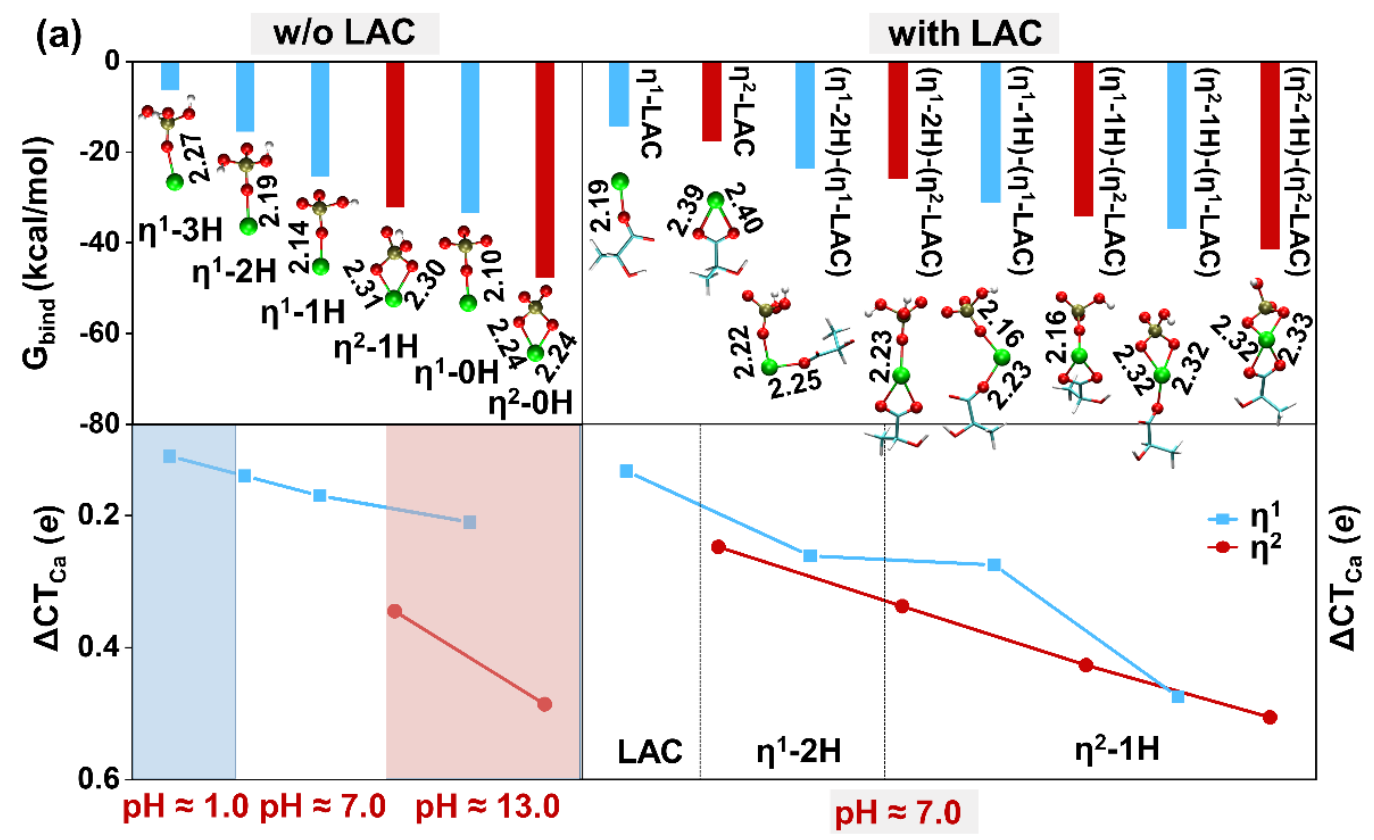

(b) with solvent molecules

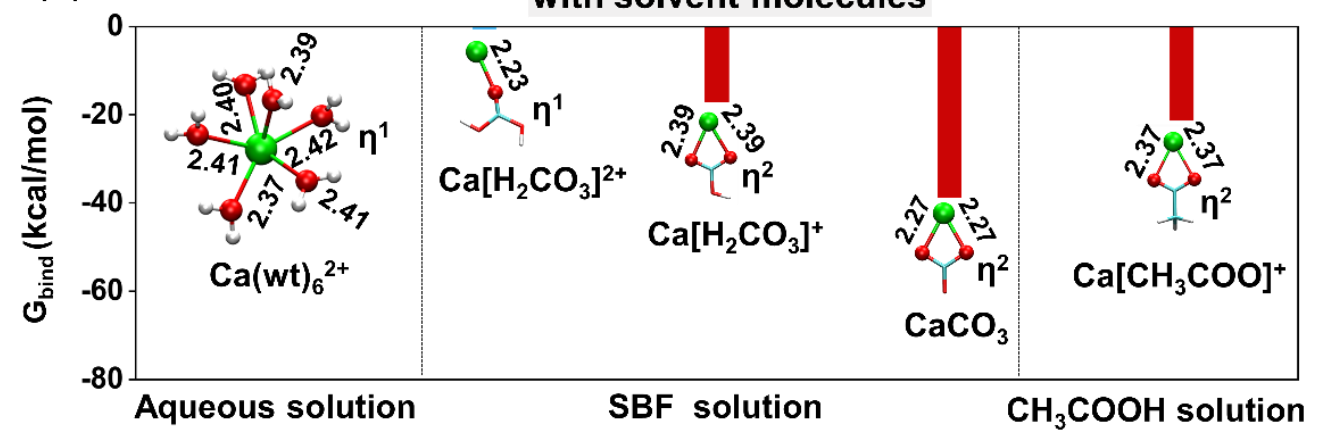

Figure 3. (a) The calculated binding free energies- $\mathrm{G}_{\mathrm{bind}}(\mathrm{kcal} / \mathrm{mol})$ of different compounds w/o and with LAC at the level of M062X/6-311+g(d,p); (b) the charge transfer extent described by charge difference between $\mathrm{Ca}^{2+}$ ion in $\mathrm{Ca}-\mathrm{O}$ binding compound and an isolated $\mathrm{Ca}^{2+}$ ion $\left(\Delta \mathrm{CT}_{\mathrm{Ca}}\right)$ of $\mathrm{CaP}$ complex without and with the attached LAC; (c) the relative binding free energies between $\mathrm{Ca}^{2+}$ ion and solvent molecules with the binding energy of the 6-coordinated water complex taken as a reference. The units of distance are $\AA$. Green balls-Ca atoms, red balls-O atoms, brown balls-P atoms, white balls-H atoms. 
Competitive interactions with LAC and solvent molecules. Besides phosphate species, $\mathrm{Ca}^{2+}$ ions could also bind with other oxygen-containing functional groups. When the $\mathrm{pH}$ is about 7, the LAC and the longer oligomers exit as the deprotonated states since the $\mathrm{pK}_{\mathrm{a}}$ values of LAC and PLA are 3.86 and $3.10^{49,57}$, respectively. As shown in Figure 3a, LAC could coordinate with $\mathrm{Ca}^{2+}$ ion both by $\eta^{1}$ and $\eta^{2}$ modes, indicating that LAC could compete with phosphate species to chelate $\mathrm{Ca}^{2+}$ ions in solution. Since the elongation of LAC oligomer from LAC monomer to $\mathrm{LAC}_{8}$, does not change the binding strength too much (Table S1), we mainly analysis the binding modes of LAC with the $\mathrm{CaP}$ clusters. As demonstrated in Figure $3 \mathrm{a}$, the stronger binding strength of $\eta^{2}$ coordination mode than $\eta^{1}$ is closely related to the extent of charge transfer between the interacting components, which was defined as $\Delta \mathrm{CT}_{\mathrm{Ca}}$ (charge variance of Ca caused by binding with phosphates without and with the presence of LAC). Thus, the electrostatics interaction is a dominating factor in tuning interfacial interactions with adding LAC or other additives and changing the $\mathrm{pH}$ conditions. With respective to the coordination of $\mathrm{Ca}^{2+}$ ion with water molecules in aqueous solution, the $\mathrm{H}_{2} \mathrm{CO}_{3}, \mathrm{CO}_{3}{ }^{2-}$, and $\mathrm{HCO}_{3}{ }^{-}$ions in SBF solution and $\mathrm{CH}_{3} \mathrm{COO}^{-}$group in $\mathrm{CH}_{3} \mathrm{COOH}$ solution may compete with phosphate species to chelate $\mathrm{Ca}^{2+}$ ions with non-negligible relative binding strengths (Figure $3 b$ ), whose effects were considered in the following MD simulations with the introduction of explicit solvent molecules. In addition, the formation of the new $\mathrm{Ca}-\mathrm{O}$ bonds with adding LAC and other oxygen-containing solvent molecules would increase the Ca-O distances which are close to phosphorus atom (Figure 3a). For example, the $\mathrm{Ca}-\mathrm{O}$ distance of $2.19 \AA$ in $\eta^{1}-2 \mathrm{H}$ is elongated to 2.22 (in $\eta^{1}$ ) or $2.23 \AA$ (in $\eta^{2}$ ) with the addition of LAC (Figures 3a). This indicates that the presence of LAC could weaken the binding ability of $\mathrm{Ca}^{2+}$ ions with phosphate species. It will be domenstrated through both MD simulations and experiments that the nucleation process of $\mathrm{CaP}$ would be slowed down by adding LAC.

It is also meaningful to survey the interfacial interactions of LAC with different HA surfaces, which represent the large sized $\mathrm{CaP}$ systems and crystallization product after nucleation. As displayed in Figure 4a, HA $(\mathrm{Ca} / \mathrm{P}=1.67)$ has a hexagonal crystal 
structure with 44 atoms in each unit cell, in which the calcium ions are situated in two different sites, denoted as Ca1 (blue color) and $\mathrm{Ca} 2$ (green color), respectively. The difference between these two different kinds of calcium ions is told by the coordination number of $\mathrm{Ca}$, called $\mathrm{N}_{\text {Ca-contact. }}$ The nine-coordinated $\mathrm{Ca} 1\left(\mathrm{~N}_{\mathrm{Ca}-\text {-contact }}=9\right)$ is surrounded by nine oxygen atoms from the surrounding six phosphate groups, and Ca2 $\left(\mathrm{N}_{\text {Ca-contact }}\right.$ $=7$ ) is coordinated to seven oxygen atoms (where six coming from phosphate groups and one from the hydroxyl group). Both $\eta^{1}$ and $\eta^{2}$ coordination modes between $\mathrm{PO}_{4}{ }^{3-}$ and $\mathrm{Ca}^{2+}$ ions coexist in HA crystal structure. The change of $\mathrm{pH}$ values could lead to the difference in $\mathrm{Ca} / \mathrm{P}$ ratios ${ }^{70}$ and hence the different morphologies of the prepared HA. ${ }^{28}$ Being stimulated by such $\mathrm{pH}$-dependent phenomena, we attempt to tune the $\mathrm{Ca} / \mathrm{P}$ ratios in our simulation models by changing the number of hydroxyl groups in HA unit cell (Figure $4 \mathrm{~b}$ ). In addition, the number of $\mathrm{Ca}^{2+}$ ions on surface per unit area, labelled as $\mathrm{N}_{\text {Ca-surface }} / \mathrm{A}$, was also changed with the different $\mathrm{Ca} / \mathrm{P}$ ratios. Here, the surface area (A) is introduced to eliminate the influence of different surfaces. The parameter of $\mathrm{N}_{\mathrm{Ca}}$ surface/ $\mathrm{A}$ is one of the factors to affect the binding ability of different HA surface facets with different $\mathrm{Ca} / \mathrm{P}$ ratios with the oxygen-containing additives.

Before we start to investigate the adsorption of LAC on HA slab, the relative stabilities of the different surfaces of HA were tested from their surface energy, $E_{\text {surf, }}$ which is the energy difference per unit area between a slab model and the bulk crystal structure. As shown in Figure S8, among the studied HA surfaces, including (001), (100), (110), (210), (211), (112), the (001) surface was predicted to be the most stable one, in agreement with those reported DFT results using B3LYP or PBE functionals. ${ }^{71-}$ ${ }^{73}$ The thickness of four layers in the slab model is enough to give a converged value of surface energy. On the contrary, the (100) surface was expected to be most active toward adsorption of additives with the largest surface energy. In the following discussion, we would focus on (001) and (100) surfaces to study the adsorption of LAC on HA with different $\mathrm{Ca} / \mathrm{P}$ ratios (Figure $4 \mathrm{c}$ ). 
(a)

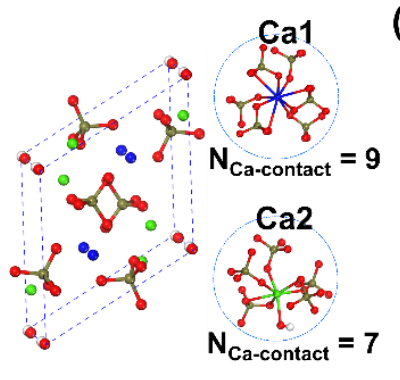

(b)

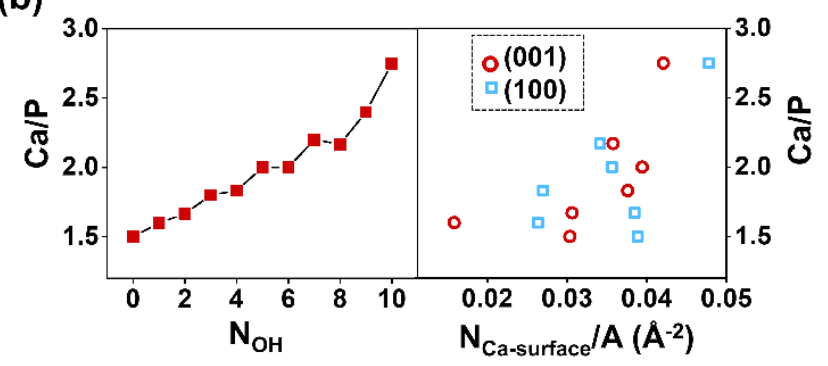

(c)

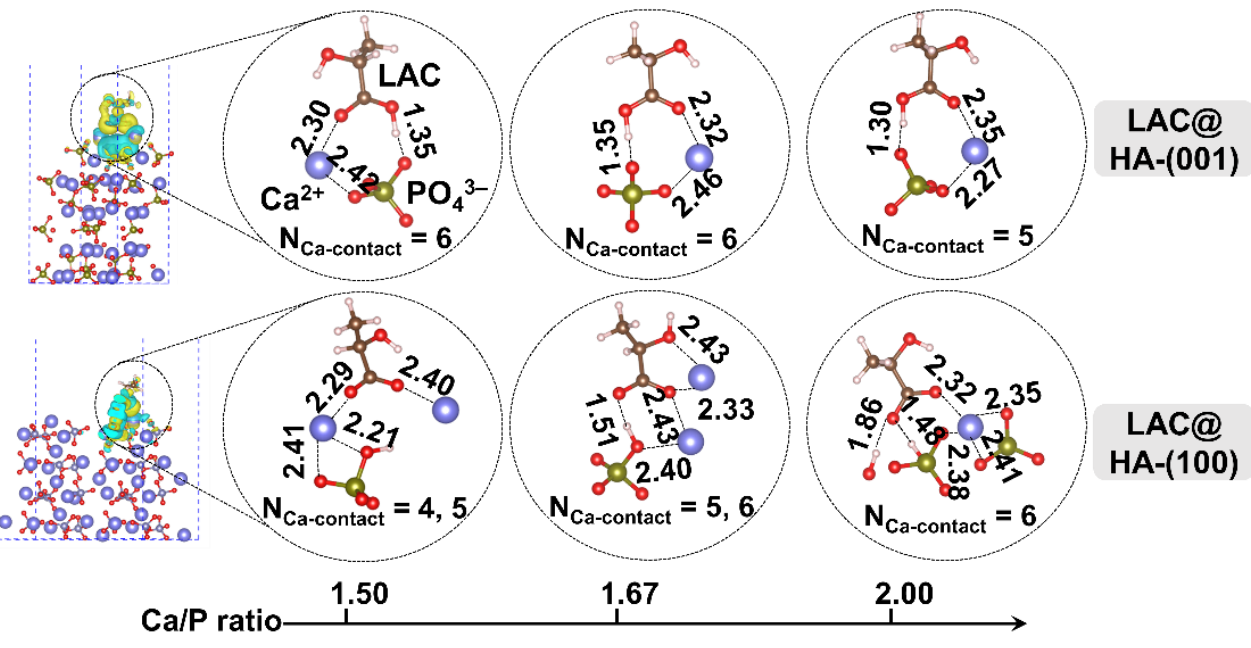

(d)

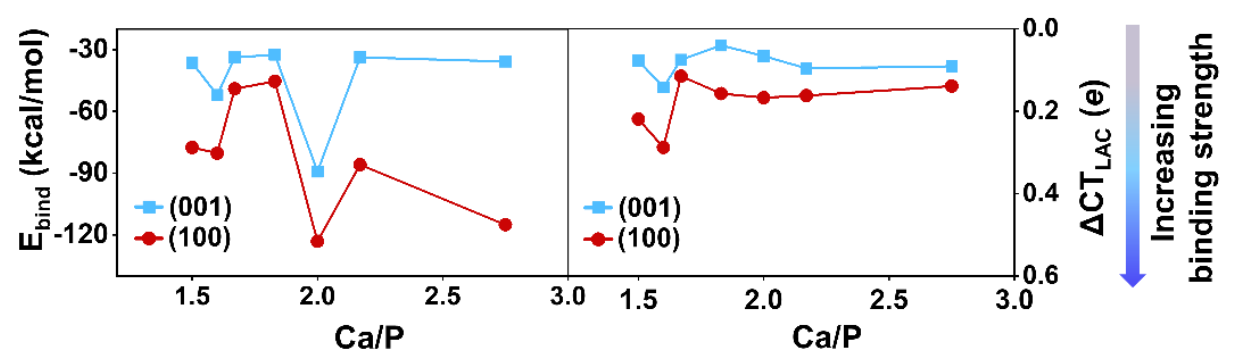

Figure 4. (a) Unit cell of HA crystal; (b) the variation of $\mathrm{Ca} / \mathrm{P}$ ratios with the number of hydroxyl groups, $\mathrm{N}_{\mathrm{OH}}$, and the number of $\mathrm{Ca}^{2+}$ ions on surface per unit area, labelled as $\mathrm{N}_{\text {Ca-surface }} / \mathrm{A}$; (c) the interfacial binding modes and (d) the binding energies ( $\left.\mathrm{E}_{\text {bind }}\right)$ of LAC with the (001) and (100) surfaces with different $\mathrm{Ca} / \mathrm{P}$ ratios. The charge transfer between the LAC and HA substrate is also displayed in (c) and (d), with the $\triangle C_{\text {LAC }}$ estimated from the charge difference between LAC and the attached LAC on HA surface. 
There are multiple interactions between LAC and HA surface including electrostatic interaction, proton transfer, and intermolecular hydrogen bond, as shown in Figure 4c. In addition to the above-mentioned $\mathrm{Ca}-\mathrm{O}$ binding with LAC, the oxygen atoms of phosphates are favorable to form the interfacial hydrogen bonding interaction with the hydroxyl group of LAC molecule. These complicated interfacial interactions leading to the significant binding strength, $E_{\text {bind, }}$ as shown in Figure $4 \mathrm{~d}$. Among the studied slab models with $\mathrm{Ca} / \mathrm{P}$ ratios changing from 1.50 to 2.75 , the $\mathrm{Ca} / \mathrm{P}$ of 2.00 corresponds to the largest $E_{\text {bind }}$ value $(-123.13 \mathrm{kcal} / \mathrm{mol}$ on the (100) surface; -89.23 $\mathrm{kcal} / \mathrm{mol}$ on the (001) surface) due to the stronger intermolecular hydrogen bonding than those of the other $\mathrm{Ca} / \mathrm{P}$ ratios. The proton transfer from LAC to surface species is also be observed on (001) and (100) surfaces of HA with different $\mathrm{Ca} / \mathrm{P}$ ratios (Figure $4 \mathrm{c}$, Table S19). The positive values of $\Delta \mathrm{CT}_{\mathrm{LAC}}$ shown in Figure $4 \mathrm{~d}$ meant that the surface acted as the electron donor and transferred charge to the LAC. This is consistent with the conclusion drawn from previous DFT study with PBE functional that the protons of adsorbates could be transferred to hydroxyl and phosphate groups on the surface. ${ }^{72}$ Compared to (001) surface, more active (100) surface owned the larger $\Delta \mathrm{CT}_{\text {LAC }}$ value, because larger number of undercoordinated surface species on (100) surface facilitates the binding of LAC with dangling bonds.

\subsection{The pH dependent coordination modes in CaP clusters}

AIMD simulations of aqueous solution without presence of additives. AIMD simulations were further carried out to provide the more detailed information of the intermolecular interactions between phosphate species and $\mathrm{Ca}^{2+}$ ions in the early aggregation stage. Some simulation settings such as the number of water molecules (92), the size of box $\left(14 \times 14 \times 14 \AA^{3}\right)$ and functional (PBE) were similar to those used in AIMD study of the prenucleation $\left[\mathrm{Ca}\left(\mathrm{HPO}_{4}\right)_{3}\right]^{4-}$ cluster with $\mathrm{PBE}$ functional. ${ }^{4}$ In the present work, we aim to study the difference in coordination modes with $\mathrm{Ca}^{2+}$ ion between different phosphate species caused by the change of $\mathrm{pH}$ conditions. The selected snapshots from AIMD trajectories of aggregation of different phosphate 
species around $\mathrm{Ca}^{2+}$ ions without (w/o) the presence of LAC are shown in Figure 5a. For $2 \mathrm{H}$ and $3 \mathrm{H}$, which are dominant protonation states in acidity condition, the major coordination of $\mathrm{Ca}^{2+}$ is in $\eta^{1}$ modes, as displayed by a single sharp peak in the radial distribution function (RDF) of Ca-P distance. To the other end, the $\mathrm{Ca}^{2+}$ coordinated with the deprotonated species of $0 \mathrm{H}$ and $1 \mathrm{H}$ in basic conditions in both $\eta^{1}$ and $\eta^{2}$ modes, corresponding to the two overlapping peaks in RDF, respectively. The $\eta^{2}$ peak of Ca $\cdots P$ distance is located around $3.1 \AA$, shorter than that $(3.7 \AA)$ in $\eta^{1}$ binding mode. This is also in line with our DFT optimizations of various $\mathrm{CaP}$ clusters in Figure 3a. For example, the $\mathrm{Ca} \cdots \mathrm{P}$ distance in the strongly bound $\eta^{2}-0 \mathrm{H}$ cluster is $2.9 \AA$, shorter than that (3.9 $\AA$ ) in $\eta^{1}$ coordination mode of $\eta^{1}-0 \mathrm{H}$. As mentioned above, the simulation of $\mathrm{pH} \approx 7.4$ involved the two coexisting $2 \mathrm{H}$ and $1 \mathrm{H}$ species, which have different binding modes toward $\mathrm{Ca}^{2+}$ ions, i.e., $2 \mathrm{H}$ is bound in $\eta^{1}$ but $1 \mathrm{H}$ is chelated in both $\eta^{1}$ and $\eta^{2}$ modes. The coexisting $\eta^{1}$ and $\eta^{2}$ modes between $\mathrm{PO}_{4}{ }^{3-}$ and $\mathrm{Ca}^{2+}$ ion were also revealed by in situ XANES experiments that the most abundant clusters were detected to be $\mathrm{Ca}\left(\eta^{2}-\mathrm{PO}_{4}{ }^{3-}\right)_{2} \mathrm{~L}_{2}\left(\mathrm{~L}=\mathrm{H}_{2} \mathrm{O}\right.$ or $\left.\eta^{1}-\mathrm{PO}_{4}{ }^{3-}\right)$ during ACP formation. ${ }^{74}$ The prenucleation $\left[\mathrm{Ca}\left(\mathrm{HPO}_{4}\right)_{3}\right]^{4-}$ cluster was found to take the configuration of $\left(\mathrm{Ca}\left(\eta^{2}-\mathrm{HPO}_{4}{ }^{2-}\right)_{2}\left(\eta^{1-}\right.\right.$ $\left.\mathrm{HPO}_{4}{ }^{2-}\right)\left(\mathrm{H}_{2} \mathrm{O}\right)_{2}$ from the AIMD study with PBE functional. ${ }^{4}$

It was found from the SDF (Figure 5a) that $\mathrm{Ca}^{2+}$ ions were mainly chelated with non-hydroxyl oxygen atoms of phosphate species. In the simulation of $\mathrm{pH} \approx 1.0$, one hydrogen atom of the $3 \mathrm{H}$ was pulled by a nearby water molecule through the hydrogen bonding. Such a hydrated proton was stabilized by the formation of concerted hydrogen bonding chain in the surrounding water solvent molecules. As a result, the $3 \mathrm{H}$ in Figure 5a looks like to 'lose' a proton to form a deprotonated $2 \mathrm{H}$ species, which was demonstrated to have stronger binding free energies than the $3 \mathrm{H}$ by our DFT results (Figure 3a). When the $\mathrm{pH}$ value is increased to 5, the more compact $\mathrm{CaP}$ cluster is formed with the two $2 \mathrm{H}$ species bridged by two $\mathrm{Ca}^{2+}$ ions through non-hydroxyl oxygen atoms of the deprotonated phosphates. The number of non-hydroxyl oxygen atoms is increased with the further deprotonations in the increased $\mathrm{pH}$ conditions, leading to the formation of the cage-like $\mathrm{CaP}$ prenucleation cluster. Each $\mathrm{Ca}^{2+}$ ion sits at the cage 
vertex to bridge $3 \sim 4$ oxygen atoms of phosphates with significant binding energies. The water molecules were pushed outside the $\mathrm{CaP}$ cluster cages, exhibiting strong tendency of forming precipitate.

(a) w/o LAC

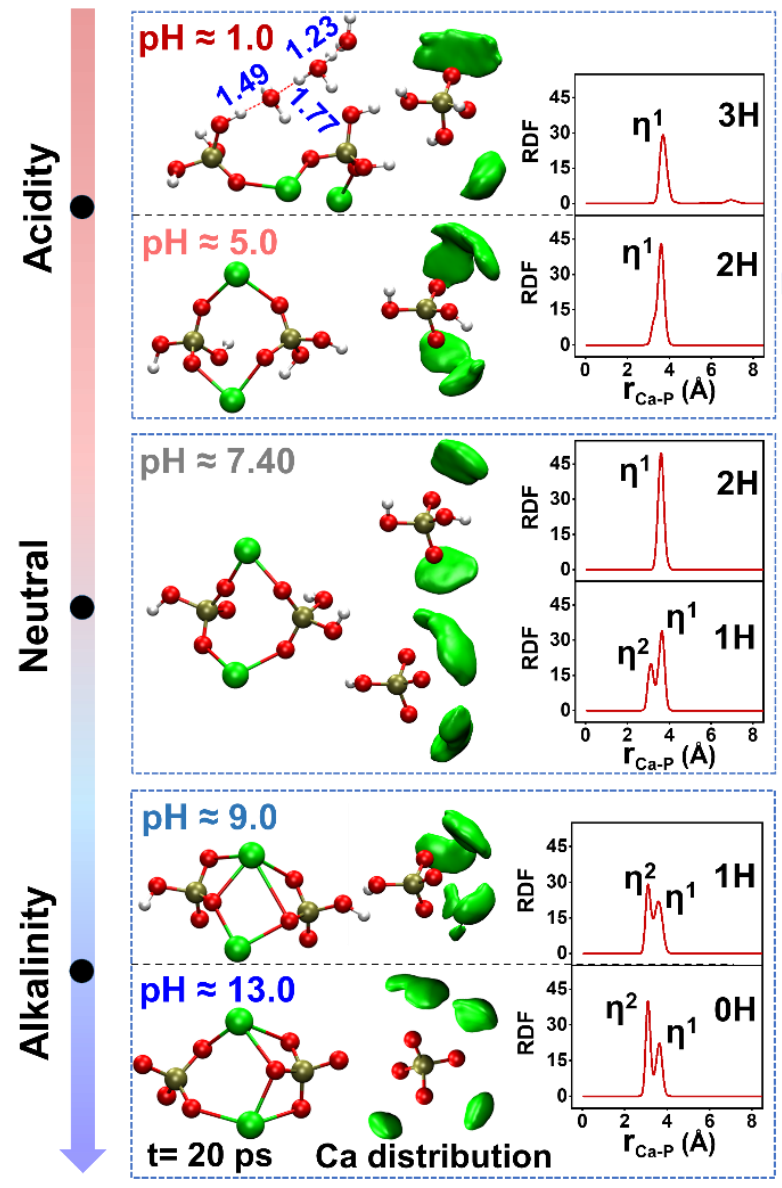

(b) with LAC
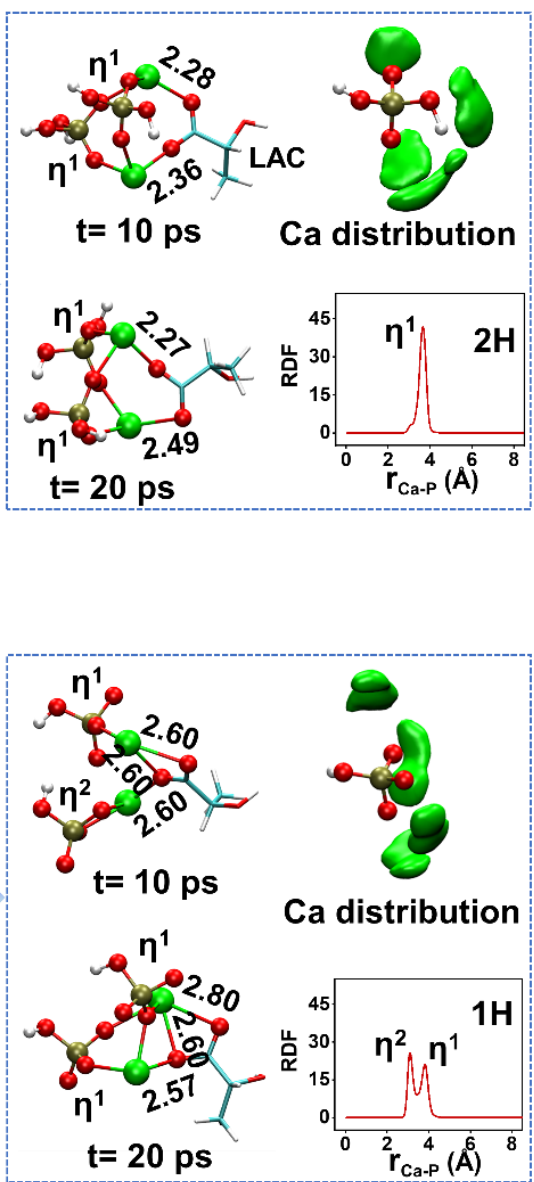

Figure 5. The selected AIMD snapshots, $\mathrm{SDF}$ (isosurfaces for $\mathrm{Ca}$ atoms are represented in green, and isovalues of Ca atoms are set to be 50 particles $/ \mathrm{nm}^{3}$ ), and RDF of studied systems (a) w/o LAC and (b) with LAC, respectively. Only the adjacent water molecules with $2.0 \AA$ are shown in the sampled snapshots at 20 ps for clarity.

\section{Influence of LAC oligmers on the coornation number and hydrogen bonding.}

The addition of LAC introduced the competitive coordination interactions with $\mathrm{Ca}^{2+}$ ions, destroying the cage structure of $\mathrm{CaP}$ cluster (Figure 5b). Consequently, the

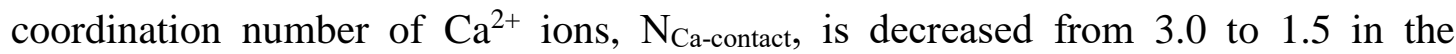


deprotonated $1 \mathrm{H}$ system in basic condition. As shown in Figure 5b, LAC would bind with $\mathrm{Ca}^{2+}$ ions in both $\eta^{2}$ and $\eta^{1}$ modes, decreasing the contact chance of phosphates with $\mathrm{Ca}^{2+}$ ions.

It is difficult to perform AIMD study on the intermolecular interactions of longer $\mathrm{LAC}_{8}$ oligomer in $\mathrm{CaP}$ aqueous solutions with different $\mathrm{pH}$ conditions due to the huge computational costs with much larger simulation boxes to accommodate the $\mathrm{LAC}_{8}$ chain (whose length was predicted to be $22.9 \AA$ by DFT optimization). To study the influence of LAC oligomers in a much larger space and time scale, we carried out classical MD simulations based on GAFF2 on three model systems: w/o additives, with LAC and with $\mathrm{LAC}_{8}$, respectively, as shown in Figures 6. To gain insight of calcium phosphate precipitation and biological mineralization in the physiological environment, the $\mathrm{SBF}$ solutions with ion concentrations and $\mathrm{pH}$ value similar to the human blood plasma $^{17-25}$ were introduced in our MD simulations. As listed in Table S20, the SBF solutions are consisting of $\mathrm{Na}^{+}, \mathrm{Cl}^{-}, \mathrm{HCO}_{3}{ }^{-}, \mathrm{K}^{+}, \mathrm{Mg}^{2+}, \mathrm{Ca}^{2+}, \mathrm{HPO}_{4}{ }^{2-}$ and $\mathrm{SO}_{4}{ }^{2-}$ ions.

It could be concluded that the coordination modes of phosphate species and $\mathrm{Ca}^{2+}$ ions obtained by GAFF2 based MD simulations (Figure 6, Figure S9) were similar to those revealed from AIMD simulations, validating the adopted force field parameters (see surporting information for the details). Compared with the control group (w/o additives), LAC molecules were mainly chelated with $\mathrm{Ca}^{2+}$ ions through its carboxyl group by $\eta^{2}$ and $\eta^{1}$ modes (Figure 6). Besides, one $\mathrm{Ca}^{2+}$ ion could chelate with two or more LAC molecules when the $\mathrm{pH}$ is larger than 5.0. In the strong acid solution of $\mathrm{pH}$ $\approx 1.0$, the LAC oligomers are not deprotonated and have little binding affinity to the $\mathrm{CaP}$ clsuters, as indicated by the long distance between the LAC additives and the $3 \mathrm{H}$ species in Figure 6. Same as what has been found in AIMD simulations, the chelation of $\mathrm{LAC}$ and $\mathrm{Ca}^{2+}$ ions reduced the number of $\mathrm{Ca}^{2+}$ ions near the phosphate species. 


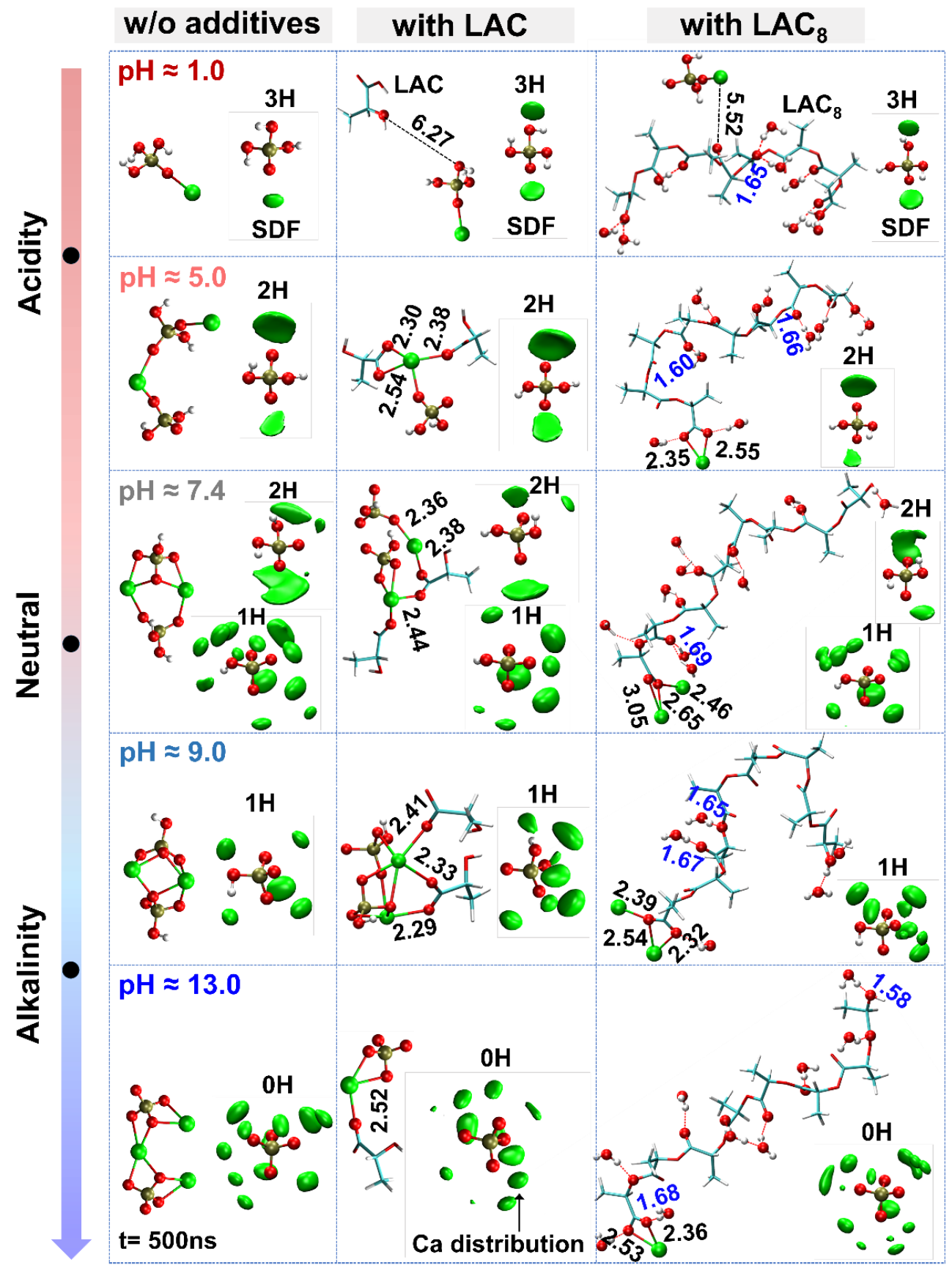

Figure 6. The selected GAFF2 based MD napshots and SDF (isosurfaces for Ca atoms are represented in green, and isovalues of Ca atoms are set to be 50 particles $/ \mathrm{nm}^{3}$ except the system with $\mathrm{pH} \approx 1.0\left(20\right.$ particles $\left.\left./ \mathrm{nm}^{3}\right)\right)$ of the CaP clusters in SBF solution w/o addidiates, with $\mathrm{LAC}$, and with $\mathrm{LAC}_{8}$, respectively. Only the adjacent water molecules with $2.0 \AA$ are shown in the sampled snapshots at 20 ps for clarity. The ions of SBF were also hidden in snapshots. 
The longer oligmer, $\mathrm{LAC}_{8}$, is facvor to take a zigzag conformation in $\mathrm{CaP}$ aqueous solution. $\mathrm{LAC}_{8}$ perferred to chelate with $\mathrm{Ca}^{2+}$ ions through its terminal carboxyl group, and the other oxygen-containing functional groups could from hydrogen bonds with nearby water molecules (Figure 6). The cage like $\mathrm{CaP}$ clsuter is diificult to form in the vincity of $\mathrm{LAC}_{8}$. To compare with the coordination modes of $\mathrm{Ca}^{2+}$ ions and phosphate species under SBF solution, the coordination modes of $\mathrm{Ca}^{2+}$ ions and phosphate species under aqueous solution with $\mathrm{pH} \approx 7.4$ were also studied (Figure S9). The exsitence of various ion compositions in SBF solution brought little difference in coordination modes of $\mathrm{CaP}$ from those in aqueous solution. The present GAFF2 based MD simulations on aqueous solution of $\mathrm{Ca}^{2+}$ ions and $0 \mathrm{H}$ species gave similar results to the previous MD simulations based on INTERFACE force field, which demonstrated the $\eta^{1}$ and $\eta^{2}$ coordination modes by the two peaks at 3.16 and $3.78 \AA$ in $\operatorname{RDF}^{39}$.

\subsection{Aggregation of CaP clusters in aqueous and SBF solutions}

In order to further trace the evolution process of $\mathrm{CaP}$ clusters at different simulation time durations, we presented the snapshots in Figure S10 at simulation time of $0 \mathrm{~ns}, 100 \mathrm{~ns}, 300 \mathrm{~ns}$ and $500 \mathrm{~ns}$, respectively. We lay emphasis on the MD simulation models with $\mathrm{pH} \approx 7.4$ and $\mathrm{Ca} / \mathrm{P}=2.00$, in which $1 \mathrm{H}$ and $2 \mathrm{H}$ phosphates were randomly distributed in the SBF solutions, as shown in Figure 7a and Figure S10a. With the evolution of MD simulation, the initial small sized and loosely bound $\mathrm{CaP}$ clusters attracted each other and aggregated into the larger clusters consisting of about $10 \mathrm{Ca}^{2+}$ ions at $500 \mathrm{~ns}$. By the end of the MD simulation, about $58 \%$ of $\mathrm{Ca}^{2+}$ ions in those $\mathrm{CaP}$ clusters were coordinated by phosphate species, and those $\mathrm{Ca}^{2+}$ ions were found at the upmost surface of the formed clusters. It could be seen from Figure $7 \mathrm{~b}$ and Figure $S 10 \mathrm{~b}$, LAC monomer could chelate with $\mathrm{Ca}^{2+}$ ions during the entire simulation time. However, the longer oligomer, $\mathrm{LAC}_{8}$, was mainly keeping free because of its weaker binding ability to $\mathrm{Ca}^{2+}$ ions than LAC monomer. It is also shown that the carboxyl group of LAC molecules could compete with phosphate species $(1 \mathrm{H}$ and $2 \mathrm{H})$ to bind with $\mathrm{Ca}^{2+}$ ions in $\eta^{1}$ and $\eta^{2}$ modes (Figures $7 \mathrm{~b}$ ). We selected two typical clusters, cluster 1 and 
cluster 2, to illustrate the binding modes of oxygen-containing groups, such as phosphates, LAC, and ions in SBF solution, with $\mathrm{Ca}^{2+}$ ions, as shown in the inset of Figure 7. In cluster 1, two bridging $\mathrm{Ca}^{2+}$ ions are in distorted tetrahedral and trihedral coordinations formed by the surrounding LAC molecules. The cluster 2 is bigger and more complicated than cluster 1 . The two $\mathrm{Ca}^{2+}$ ions in cluster 2 binding with two LAC monomers and $2 \mathrm{H}$ phosphates through trihedral and bilateral coordinations, while all of the other three $\mathrm{Ca}^{2+}$ ions are tetrahedrally coordinated with the surrounding $1 \mathrm{H}$ species to form a compact $\mathrm{CaP}$ cage. There were still several free $2 \mathrm{H}$ species that did not coordinate with $\mathrm{Ca}^{2+}$ ions during $500 \mathrm{~ns}$ MD simulation (Figure $\mathrm{S} 11$ ) because of its relatively weaker chelate affinity to $\mathrm{Ca}^{2+}$ ions than $1 \mathrm{H}$. The CSFF based MD study of interaction between $\mathrm{CaP}$ and cellulose nanofibrils gave a similar conclusion that the activity of hydroxyl groups of substrate was not high enough to cause adsorption of $\mathrm{Ca}^{2+}$ ions from the solution. ${ }^{37}$ 
(a) w/o additives

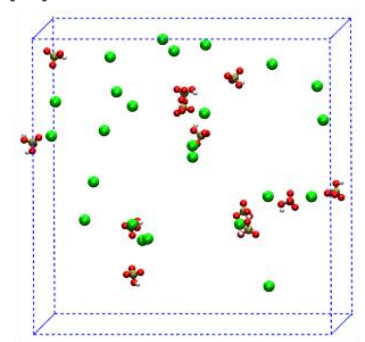

(b) with LAC

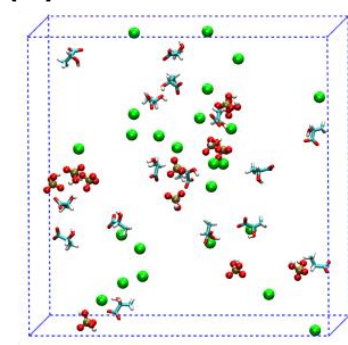

(c) with $\mathrm{LAC}_{8}$

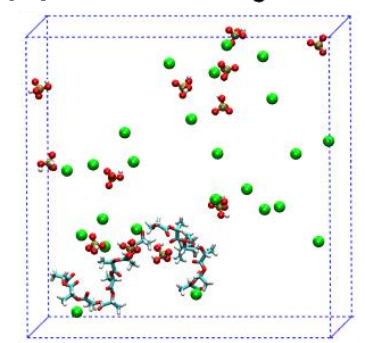

Time

O ns
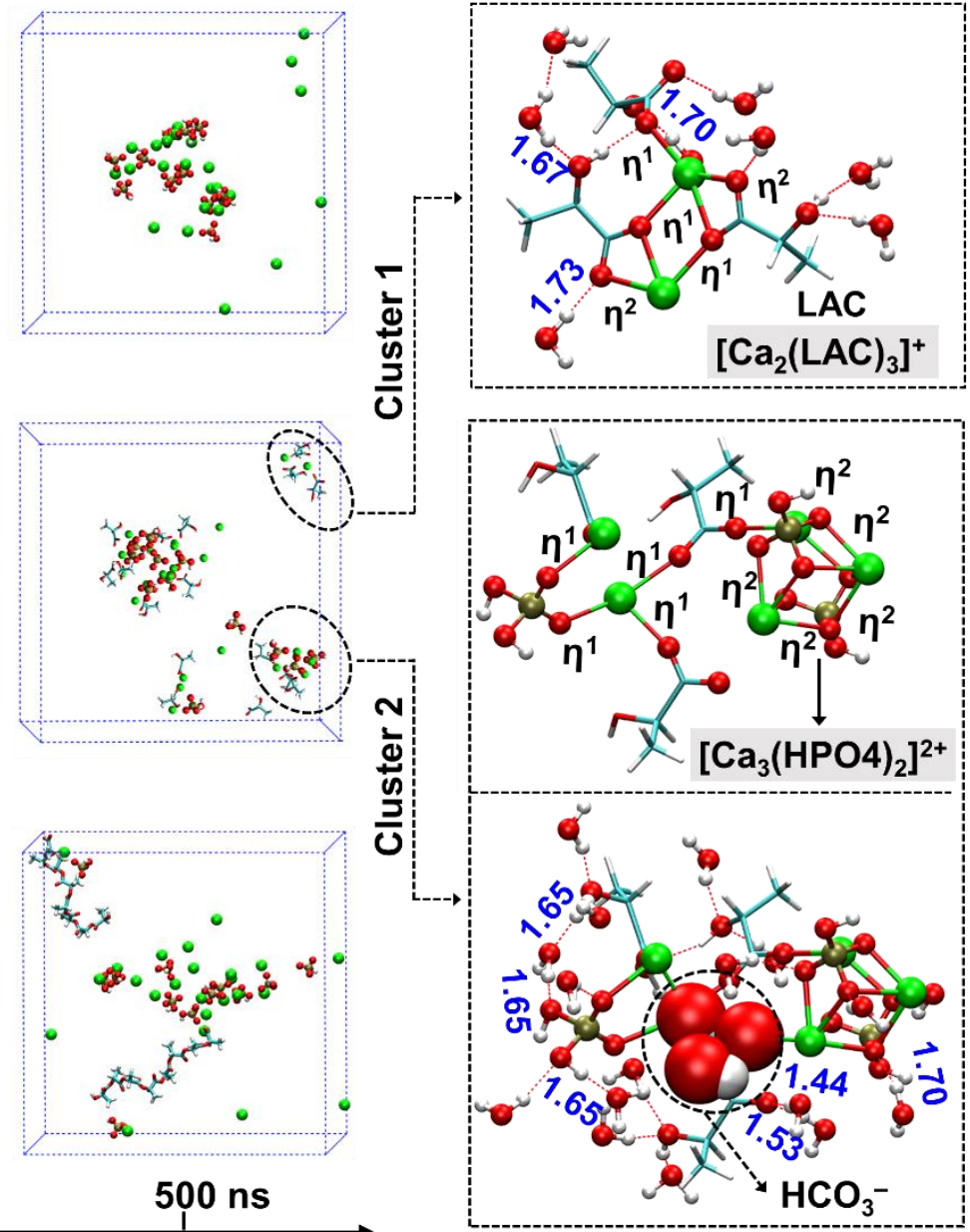

Figure 7. MD snapshots with the explicit illustration of $\mathrm{Ca}^{2+}$ ions, $1 \mathrm{H}, 2 \mathrm{H}$ ions, LAC and $\mathrm{LAC}_{8}$ at $0 \mathrm{~ns}$ and $500 \mathrm{~ns}$ of $\mathrm{CaP}$ systems $(\mathrm{Ca} / \mathrm{P}=2.00, \mathrm{pH} \approx 7.4)$ in $\mathrm{SBF}$ solutions (a) w/o additives, (b) with LAC and (c) with $\mathrm{LAC}_{8}$, respectively. Water molecules are omitted for clarity. $\mathrm{Ca}^{2+}$ ions are shown as green (VDW), $1 \mathrm{H}$ and $2 \mathrm{H}$ ions as $\mathrm{CPK}$ and VDW, LAC and $\mathrm{LAC}_{8}$ as Licorice.

Some other oxygen-containing units such as $\mathrm{HCO}_{3}{ }^{-}$ions of $\mathrm{SBF}$ solution also competed with phosphate species to chelate $\mathrm{Ca}^{2+}$ ions through $\mathrm{Ca}-\mathrm{O}$ ionic bonding. It is hence not surprising to find from our MD simulations that larger sized $\mathrm{CaP}$ clusters could be formed in a shorter simulation time under aqueous solution compared with that under SBF solution (Figure S12). For example, the snapshots at $100 \mathrm{~ns}$ for aqueous solution displayed a cluster that enclosing $11 \mathrm{Ca}^{2+}$ ions, larger than that $\left(6 \mathrm{Ca}^{2+}\right.$ ions $)$ 
appeared in SBF solution (Figures S12a, S10a). In other words, the lack of competitive interactions of $\mathrm{HCO}_{3}{ }^{-}$ions in aqueous solution could give more chance for phosphate species binding to $\mathrm{Ca}^{2+}$ ions, resulting in the formation of a larger $\mathrm{CaP}$ cluster with a short simulation time. In addition, LAC could form hydrogen bonds with nearby water molecules through its hydroxyl and carbonyl groups. Phosphate species could also function as hydrogen bonding donor or acceptor in binding with the water solvent molecules through its oxygen atoms and hydrogen atom of hydroxyl group.

MD simulations of basic conditions with $\mathrm{pH} \approx 9.0$ and $\mathrm{pH} \approx 13.0$ (Figures S13$\mathrm{S} 14$ ) demonstrated similar aggregation behavior of $\mathrm{CaP}$ clusters to the case of $\mathrm{pH} \approx 7.4$. But in the acid solution, $3 \mathrm{H}$ species owned the weak binding strength with $\mathrm{Ca}^{2+}$ ions and only small $\mathrm{CaP}$ clusters containing 2-3 $\mathrm{Ca}^{2+}$ ions were formed even at $500 \mathrm{~ns}$ trajectory (Figure S15). Nearly $92 \% \mathrm{Ca}^{2+}$ ions and $83 \% 3 \mathrm{H}$ phosphates were staying in the free state with addition of LAC (Figure S15b).

In order to evaluate the whole evolution process of clusters aggregation with a qualitative descriptor, we counted the number of phosphate species and $\mathrm{Ca}^{2+}$ ions in each cluster. In the first step, we calculated the radial distribution functions (RDF) of Ca-P (phosphate species) (Figure S16), and then the cutoff distance (R) was set based on the local minimum of corresponding RDF. Accordingly, the number of phosphate species or $\mathrm{Ca}^{2+}$ ions in each cluster was counted within the cutoff radius $\mathrm{R}$. In our code, we took one of the $\mathrm{Ca}^{2+}$ or phosphates as the center, and searched all the target species (Figure S17). Here, we selected the largest $\mathrm{CaP}$ cluster to estimate the value of $\mathrm{N}_{\mathrm{Ca}}$ contact, which represents the number of $\mathrm{Ca}^{2+}$ ions around phosphate species within the cutoff radius, with the results shown in Figures S18-S24. An increase in $\mathrm{N}_{\text {Ca-contact }}$ was observed from Figures S18, S20, S23 as the simulation time increases. The chelation of LAC with $\mathrm{Ca}^{2+}$ in $\eta^{1}$ and $\eta^{2}$ modes prevented $\mathrm{Ca}^{2+}$ ions from binding with phosphate species, yielding small value of $\mathrm{N}_{\text {Ca-contact }}$ in the neutral and alkaline conditions with different $\mathrm{Ca} / \mathrm{P}$ ratios (Figures S18, S20, S23). In contrast, the presence of $\mathrm{LAC}_{8}$ had little effect on the size of the largest $\mathrm{CaP}$ cluster and the number of $\mathrm{N}_{\text {Ca-contact }}$ (as shown 
in Figures S18, S20, S23) because of its weaker binding ability to $\mathrm{Ca}^{2+}$ ions in all $\mathrm{pH}$ conditions.

Electrostatic potential surfaces (EPS) of CaP clusters. The uneven charge distrubtion at the surface of the $\mathrm{CaP}$ cluster leads to the significant electrostatic interactions, which would play an important role in the binding affinities toward proteins and nucleation processes. In our recent work, the nano-sized CaP clusters had been found to have binding specificity toward AP2 protein through electrostatic interactions with the charged residues. ${ }^{44}$ We are now curious about the change of electrostatic potential distribution of the $\mathrm{CaP}$ aggregates upon the complexation with LAC oligomers, $\operatorname{LAC}_{n}(n=1,8)$. As shown in Figure 8, without the presence of additives the CaP clusters had unevenly distributed EPS maps, in which the exposed groups are dominated by the positively charged calcium ions (blue color) on the cluster surfaces under both acid and basic conditions. Those exposed $\mathrm{Ca}^{2+}$ ions could be coordinated with nearby water molecules to stabilize the clusters. The addition of LAC led to the charge redistribution to allow negnatively charged phosphate species (red color) being exposed at the outmost surface of CaP cluster. This was because LAC could compete with phosphate species to chelate with $\mathrm{Ca}^{2+}$ ions in both $\eta^{1}$ and $\eta^{2}$ modes, resulting in the exposed species to be phosphate species instead of $\mathrm{Ca}^{2+}$ ions. However, the relatively weaker electrostatic interaction between $\mathrm{LAC}_{8}$ and $\mathrm{Ca}^{2+}$ ions did not result in such a large change in the EPS of CaP cluster as what was found above with the additive of LAC monomer. 


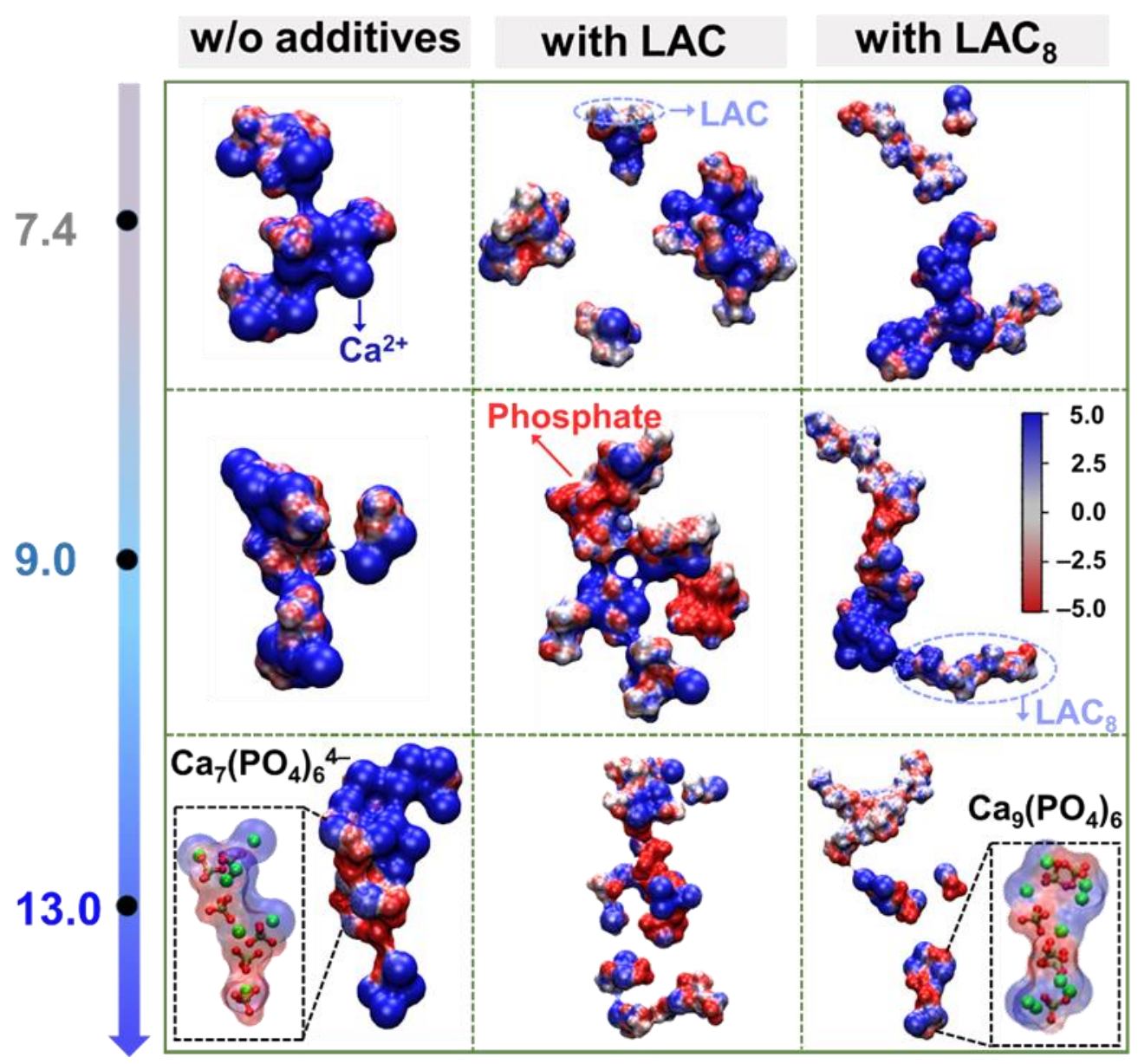

Figure 8. Electrostatic potential surface maps of $\mathrm{CaP}$ clusters without and with $\mathrm{LAC}_{\mathrm{n}}$ oligomers $(\mathrm{n}=1,8)$ under different $\mathrm{pH}$ values $(\mathrm{Ca} / \mathrm{P}=2.00)$ sampled at $500 \mathrm{~ns}$ of $\mathrm{MD}$ simulation. The electrostatic potentials are calculated with APBS software. The unit for electrostatic potential is $\mathrm{k}_{\mathrm{B}} \mathrm{T} / e$.

Moreover, our MD simulations demonstrated the formation of the Posner-like clusters, such as Ca-deficient complex $\left[\mathrm{Ca}_{7}\left(\mathrm{PO}_{4}\right)_{6}\right]^{4-}$ and Posner's cluster $\mathrm{Ca} 9\left(\mathrm{PO}_{4}\right)_{6}$ (Figure 6). The Ponser's cluster ${ }^{75}$ was usually considered to be crucial in the nucleation process of $\mathrm{CaP}$ in solution. It was also reported from classical molecular dynamics simulations that $\mathrm{PO}_{4}{ }^{3-}$ and $\mathrm{Ca}^{2+}$ ions could aggregate into a $\left[\mathrm{Ca}_{8}\left(\mathrm{PO}_{4}\right)_{6}\right]^{2-}$ cluster, which is similar to Posner's cluster. ${ }^{9}$ Those small sized CaP clusters could also be assembled in the form of multiple Posner's clusters such as $\mathrm{Ca}_{108}\left(\mathrm{PO}_{4}\right)_{72}(\mathrm{OH})_{10}$ (called Ponser 12 ) on the collagen surface. ${ }^{39}$ The electrostatic interaction between the positively charged 
argnine residue and $\mathrm{PO}_{4}{ }^{3-}$ ion could regulate the $\mathrm{HA}$ nucleation process by the arginine residue of collagen. ${ }^{40}$ The distribution of postively and negatively charged groups at the $\mathrm{CaP}$ cluster surface could be correlated with the zeta potential experiments in the following subsection.

\subsection{High-throughput experimentations (HTE) of CaP clustering processes}

The above mentioned calculation results have shown that the nucleation process of $\mathrm{CaP}$ was controlled by comprehensive factors including the $\mathrm{pH}$ value, $\mathrm{Ca} / \mathrm{P}$ ratio, additives, and solvent molecules. Thus, in order to further explore the influence of those factors on the nucleation process at macroscopic scales, the HTE technique was applied to synthesize various nanoparticles of $\mathrm{CaP}$ in the present work. The experimental details were introduced in the Supporting Information. Totally 120 experimental groups were prepared based on the three factors, i.e., w/o and with the addition of LAC (factor 1), changing $\mathrm{Ca} / \mathrm{P}$ ratios from 1.20 to 2.50 (factor 2), and using different solvent media (factor 3), with the results shown in Figure 9. The UV-Vis absorbance values were used to detect the amount of the formed precipitation. It can be found from Figure $9 a$ and $9 b$ that the UV-Vis absorbance values decreased with addition of LAC in both SBF and aqeuous solutions, indicating that the addition of LAC would inhibit the generation of precipitation. As the $\mathrm{Ca} / \mathrm{P}$ ratio was greater than 2.0 , the presence of $\mathrm{LAC}$ had small effect on the amount of precipitation with the concentration of $\mathrm{Ca}^{2+}$ ions, $\left[\mathrm{Ca}^{2+}\right]$, of about $0.01 \mathrm{~mol} \cdot \mathrm{dm}^{-3}$. If the $\mathrm{Ca}^{2+}$ concentration was too low, $\left[\mathrm{Ca}^{2+}\right]=0.005 \mathrm{~mol} \cdot \mathrm{dm}^{-3}$, the UV-Vis absorbance of $\mathrm{CaP}$ aqueous solution vanished without and with the presence of LAC. It could be concluded from the above experiments that the addition of LAC inhibited the nucleation process of $\mathrm{CaP}$, supporting the foregoing theoretical predictions. 
(a) $\mathrm{SBF}$ solution $(\mathrm{pH} \approx 7.4)$
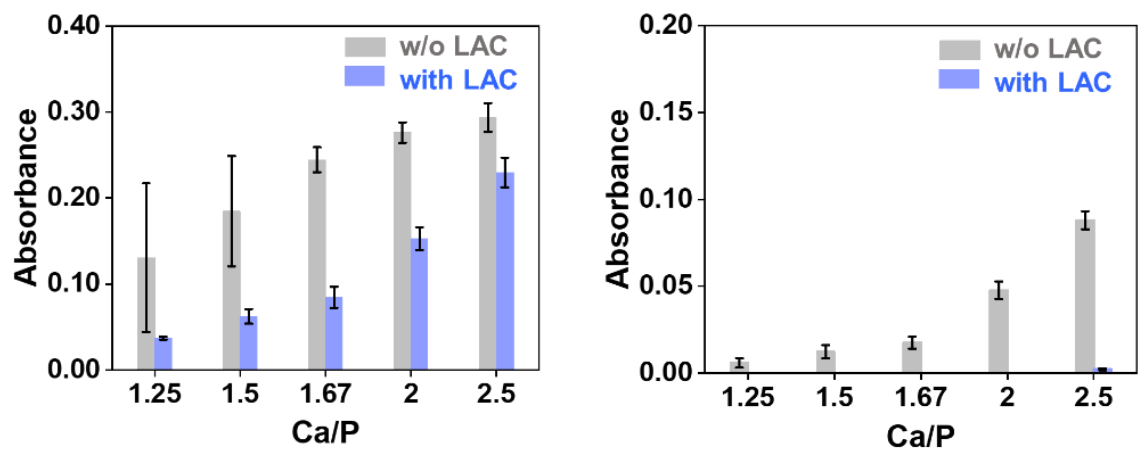

(b) Aqueous solution $(\mathrm{pH} \approx 7.4)$
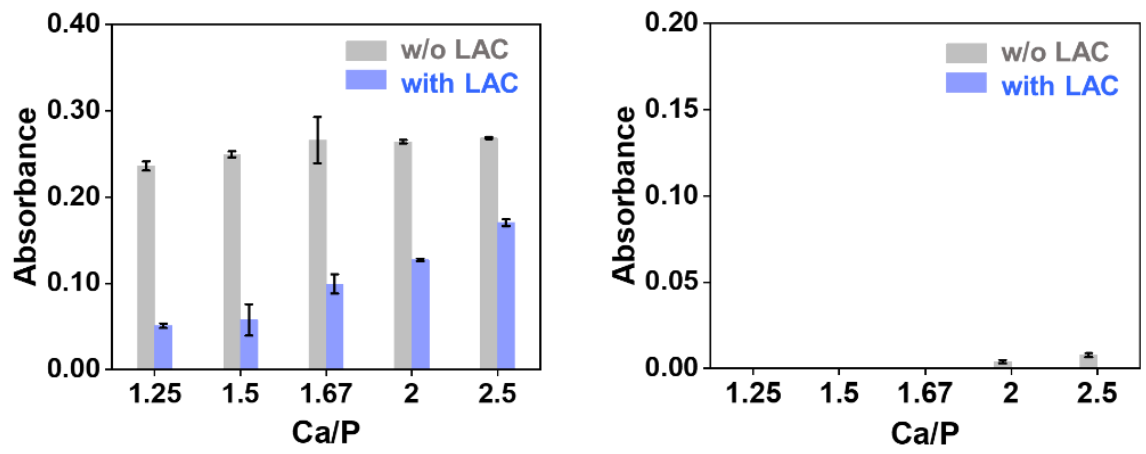

(c) Zeta potential
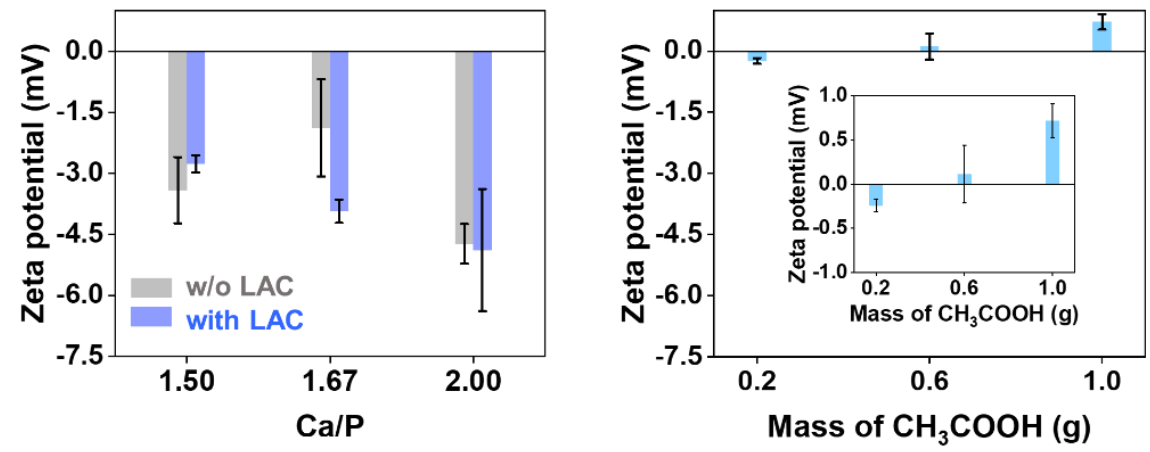

Figure 9. The absorbance values $(450 \mathrm{~nm})$ of the experimental groups with different $\mathrm{Ca} / \mathrm{P}$ ratios under (a) SBF solution and (b) aqueous solution before and after adding $\mathrm{LAC}$, where the concentrations of $\mathrm{Ca}^{2+}$ ions are $0.01 \mathrm{~mol} \cdot \mathrm{dm}^{-3}$ (left) and $0.005 \mathrm{~mol} \cdot \mathrm{dm}^{-}$ ${ }^{3}$ (right), respectively, (c) zeta potentials of $\mathrm{CaP}$ with different $\mathrm{Ca} / \mathrm{P}$ ratios and asprepared samples with different mass of $\mathrm{CH}_{3} \mathrm{COOH}$.

Zeta potential was used to estimate the average surface electronegativities. We selected three experimental groups with $\mathrm{Ca} / \mathrm{P}$ of $1.50\left(\mathrm{CaP}_{1.50}\right), 1.67\left(\mathrm{CaP}_{1.67}\right)$ and 2.00 
$\left(\mathrm{CaP}_{2.00}\right)$, respectively, to measure their zeta potentials by increasing the concentration of $\mathrm{Ca}^{2+}$ ion to $0.15 \mathrm{~mol} \cdot \mathrm{dm}^{-3}$. All these three samples had negative zeta potentials (Figure 9c, Table 1), indicating that they had net negative surface charges. The presence of LAC caused a slight increase in the zeta potentials of the samples $\mathrm{CaP}_{1.67}$ and $\mathrm{CaP}_{2.00}$ with different $\mathrm{Ca} / \mathrm{P}$ ratios. Although the zeta potential values measured by different research groups may be different from each other, the experimental data of various nanoparticles collected in Table 1 could still give some general trends, especially for the potential of binding with the biological moelcules. As shown in Table 1, the HA nanoparticles with different morphologies, ${ }^{14} \mathrm{Ag} @ \mathrm{HA},{ }^{30} \mathrm{~F}-\mathrm{Cl} @ \mathrm{HA},{ }^{31}$ and $\mathrm{Au} / \mathrm{Ag} @$ $\mathrm{HA},{ }^{35}$ had negative zeta potentials, some of which were found to be efficiently taken up by A375 cells and MG-63 cells. The HA particles with several kinds of oxygencontaining addtives, such as, citric acid@HA, ${ }^{32}$ oxalic acid@ $\mathrm{HA}^{33}$ and malic acid@ $\mathrm{HA}^{34}$ also exhibited negative zeta potentials, whose values were dependent on the $\mathrm{pH}$ values (Table 1), Similar to HA nanoparticles, some other nanoparticles including $\mathrm{Au} / \mathrm{Ag}$ nanoparticles, ${ }^{35}$ cerium oxide nanoparticles ${ }^{76}$ and iron oxide nanoparticles ${ }^{29}$ with negative zeta potentials were able to effectively absorbed on MG63, A549, and HeLa cells. In addition to the aforementioned nanoparticles, twodimensional materials such as arsenene could inhibit the proliferation of NB4 cancer cells $(82 \%$ inhibition) with the negative zeta potential $(-17.8 \mathrm{mV})$, small size, and the planar structure. ${ }^{36}$ It was addressed that highly negative zeta potential contributed to accumulate on $\mathrm{Ca}^{2+}$ ions, which was conductive to bone regeneration, thus enhanced the bioactivity of the nanoparticle. ${ }^{30}$ On the contray, low zeta potential would lead to aggregation or coagulation of nanoparticles, favored by interparticle interaction. To summary, the surface electronegativities and zeta potential could be taken as one of the descriptors in understanding the aggregation and biological functions of $\mathrm{CaP}$ particles. 
Table 1. The zeta potential values of the as-prepared $\mathrm{CaP}$ samples and some other nanoparticles with and without additives.

\begin{tabular}{|c|c|c|c|}
\hline Samples & Zeta potential $(\mathrm{mV})$ & Tumor cells & References \\
\hline \multicolumn{4}{|c|}{$\mathrm{CaP}$ with additives } \\
\hline LAC@CaP 1.50 & $-2.77 \pm 0.21(\mathrm{pH} \approx 7.4)$ & / & This work \\
\hline LAC@CaP 1.67 & $-3.92 \pm 0.29(\mathrm{pH} \approx 7.4)$ & / & This work \\
\hline LAC@CaP2.00 & $-4.89 \pm 1.50(\mathrm{pH} \approx 7.4)$ & I & This work \\
\hline Citric acid@HA & $0.00 \sim-50.00(\mathrm{pH}=3 \sim 11)$ & l & 32 \\
\hline Oxalic acid@HA & $0.00 \sim-40.00(\mathrm{pH}=4 \sim 11)$ & / & 33 \\
\hline Malic acid@HA & $0.00 \sim-20.00(\mathrm{pH}=5 \sim 11)$ & / & 34 \\
\hline \multicolumn{4}{|c|}{$\mathrm{CaP}$ or HA nanoparticles without additives } \\
\hline $\mathrm{CaP}_{1.50}(\mathrm{Ca} / \mathrm{P}=1.50)$ & $-3.41 \pm 0.82(\mathrm{pH} \approx 7.4)$ & / & This work \\
\hline $\mathrm{CaP}_{1.67}(\mathrm{Ca} / \mathrm{P}=1.67)$ & $-1.88 \pm 1.20(\mathrm{pH} \approx 7.4)$ & / & This work \\
\hline $\mathrm{CaP}_{2.00}(\mathrm{Ca} / \mathrm{P}=2.00)$ & $-4.73 \pm 0.49(\mathrm{pH} \approx 7.4)$ & / & This work \\
\hline $\mathrm{HA}-\mathrm{A}(\mathrm{Ca} / \mathrm{P}=1.67)$ & $-9.62 \pm 0.65(\mathrm{pH} \approx 10.0)$ & A375 cells & 14 \\
\hline HA-B (Ca/P=1.67) & $-10.90 \pm 0.91(\mathrm{pH} \approx 10.0)$ & A375 cells & 14 \\
\hline $\mathrm{HA}-\mathrm{C}(\mathrm{Ca} / \mathrm{P}=1.67)$ & $-12.50 \pm 0.78(\mathrm{pH} \approx 10.0)$ & A375 cells & 14 \\
\hline HA-D (Ca/P=1.67) & $-16.60 \pm 0.60(\mathrm{pH} \approx 10.0)$ & A375 cells & 14 \\
\hline $\mathrm{HA}-\mathrm{E}(\mathrm{Ca} / \mathrm{P}=1.67)$ & $-10.60 \pm 0.69(\mathrm{pH} \approx 10.0)$ & A375 cells & 14 \\
\hline $\mathrm{HA} \quad(\mathrm{Ca} / \mathrm{P}=1.21)$ & $-2.0(\mathrm{pH} \approx 7.2)$ & MG-63 cells & 35 \\
\hline Au@HA & $-15.0(\mathrm{pH} \approx 7.2)$ & MG-63 cells & 35 \\
\hline $\mathrm{Ag} @ \mathrm{HA}$ & $-13.4(\mathrm{pH} \approx 7.2)$ & MG-63 cells & 35 \\
\hline Au-Ag@HA & $-11.6(\mathrm{pH} \approx 7.2)$ & MG-63 cells & 35 \\
\hline Ag@HA & $10.0 \sim-25.0(\mathrm{pH}=4 \sim 11)$ & l & 30 \\
\hline F-Cl@HA & $-17.0 \sim-37.0(\mathrm{pH}=5,7.4,9)$ & l & 31 \\
\hline \multicolumn{4}{|c|}{ Other nanoparticles } \\
\hline $\mathrm{Au}-\mathrm{NP}$ & $-31.5(\mathrm{pH} \approx 7.2)$ & MG-63 cells & 35 \\
\hline $\mathrm{Ag}-\mathrm{NP}$ & $-26.72(\mathrm{pH} \approx 7.2)$ & MG-63 cells & 35 \\
\hline $\mathrm{Au}-\mathrm{Ag}-\mathrm{NP}$ & $-5.93(\mathrm{pH} \approx 7.2)$ & MG-63 cells & 35 \\
\hline Cerium oxide -1 & $-16.26(\mathrm{pH} \approx 7.0)$ & A549 cells & 76 \\
\hline Cerium oxide -2 & $-43.10(\mathrm{pH} \approx 13.0)$ & A549 cells & 76 \\
\hline Cerium oxide-5 & $-42.46(\mathrm{pH} \approx 13.0)$ & A549 cells & 76 \\
\hline Iron oxide & $-9.0 \sim-45.0(\mathrm{pH}=1 \sim 13)$ & HeLa cells & 29 \\
\hline
\end{tabular}

A CaP implant is partially dissolved and releases calcium and phosphate ions into the surrounding body fluid, resulting in an increase in the concentrations of calcium and phosphate ions in a local region under physiological environment. It was also interesting to study the role of LAC in nucleation process by increasing the concentrations of calcium and phosphate, so that the prepared samples were large 
enough to get their XRD patterns (Figure 10a and Figure S25) The characteristic peaks of (020), (021), (041) without and with the addition of LAC were in good agreement with the standard XRD pattern for DCPD (JCPDS: 09-0077), which indicated that all of them were composed of DCPD phase. It could be seen that the intensity of characteristic peaks such as (020), (021), (041) fluctuated with the increase of the stirring time (Figure 10b), which indicated that the nucleation of $\mathrm{CaP}$ was a dynamic process in solution. It was reported that DCPD was the most kinetically favorable phase in the precipitation, when the concentrations of calcium and phosphate are $1 \sim$ 5 times higher than those in the normal SBF solution at $\mathrm{pH}$ vlaues of 5, 7.4, and 10, respectively ${ }^{77}$ DCPD was generally regarded as a precursor phase for HA formation. ${ }^{78}$, ${ }^{79}$ As revealed in Figure S25c, the differences in the observed XRD patterns at different reaction times were insignificant, particularly when the stirring time was less than 24 h. The peaks at about $25.90^{\circ}$ and $31.86^{\circ}$ with the prepared samples at $24 \mathrm{~h}$ were consistent with the standard card (JCPDS: 09-0432)'s (002) and (211) reflection, suggesting that the prepared samples were HA. It means that DCPD could act as an intermediate phase during the formation of HA. The relative stability of DCPD could be rationalized by the relatively large binding free energy of the deprotonated $1 \mathrm{H}$ species with $\mathrm{Ca}^{2+}$ ions. The as-prepared samples showed the plate-like morphology with a dimension of 100-200 $\mathrm{nm}$ by transmission electron microscopy (TEM) without and with the addtition of LAC (Figure 10c and Figure S26). 

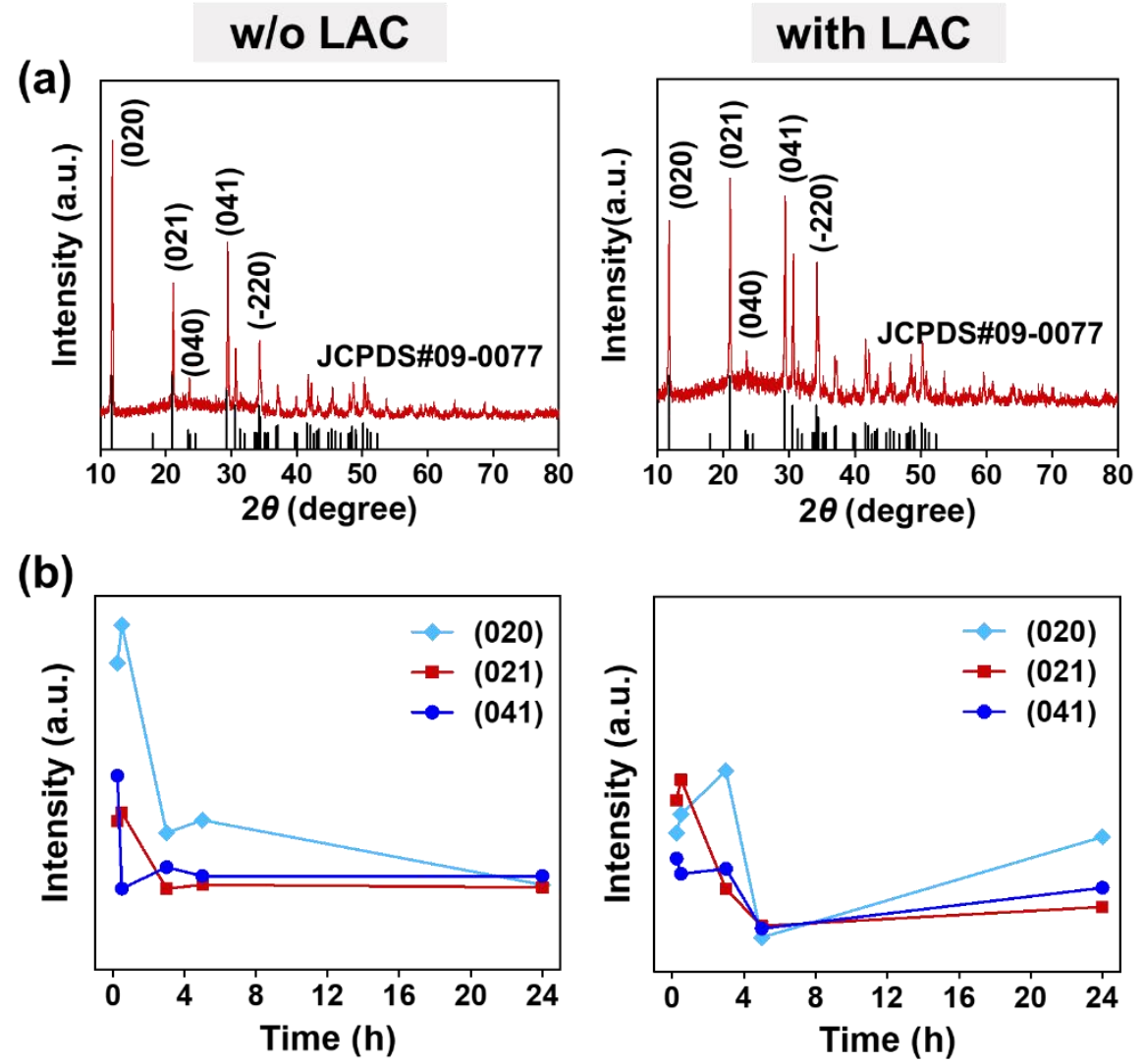

(c)
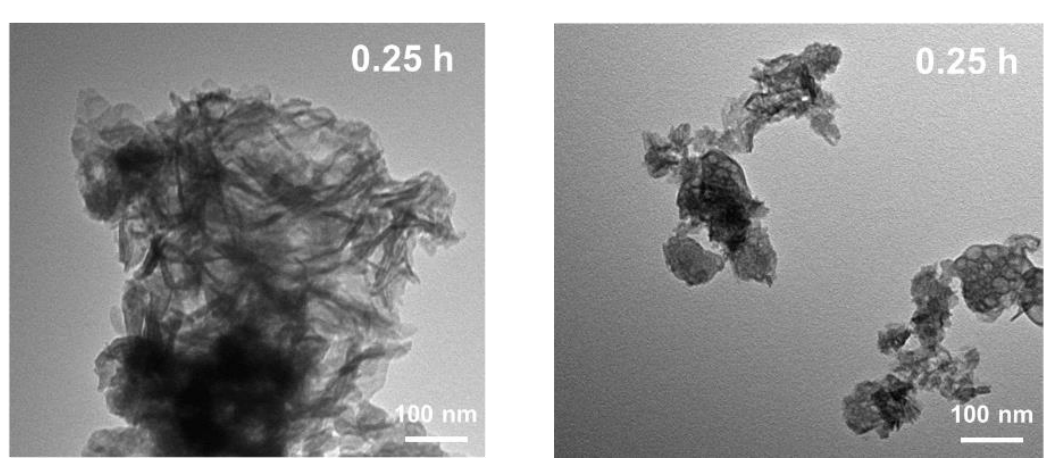

Figure 10. (a) XRD patterns, (b) intensity of characteristic peaks such as (020), (021), (041), (c) TEM images of the as-prepared samples, which were formed after $0.25 \mathrm{~h}$ of drying in a vacuum oven.

In addition, we used another method to prepare DCPD with the introduction of $\mathrm{CH}_{3} \mathrm{COOH}$ in aqueous solutuon, with the preparation process referred to the litertur ${ }^{80}$, as shown in Figure 11a. With the increase of mass of $\mathrm{CH}_{3} \mathrm{COOH}$ from 0.10 to 1.00 $\mathrm{g}$ (factor 1), the final precipitate was composed of $\mathrm{DCPD}$ and $\mathrm{Ca}(\mathrm{OH})_{2}$, judged by the characteristic XRD peaks (JCPDS: 09-0077 and 44-1481). The intensity of 
characteristic peaks at about $11.68^{\circ}(020)$ and $20.93^{\circ}(021)$ of DCPD, $18.01^{\circ}(001)$ and $34.10^{\circ}$ (101) of $\mathrm{Ca}(\mathrm{OH})_{2}$ fluctuated greatly when the mass of $\mathrm{CH}_{3} \mathrm{COOH}$ was increased from 0.40 to $0.70 \mathrm{~g}$ (Figure $11 \mathrm{~b}$ ). The zeta potentials of samples with mass of $\mathrm{CH}_{3} \mathrm{COOH}$ of $0.2,0.6$ and $1.0 \mathrm{~g}$ were also analyzed, respectively. As shown in Figure 9c, the as-prepared samples had neutral surface net charges, favoring the formation of the larger sized precipitation.

(a)
(Adding $\mathrm{CH}_{3} \mathrm{COOH}$ )
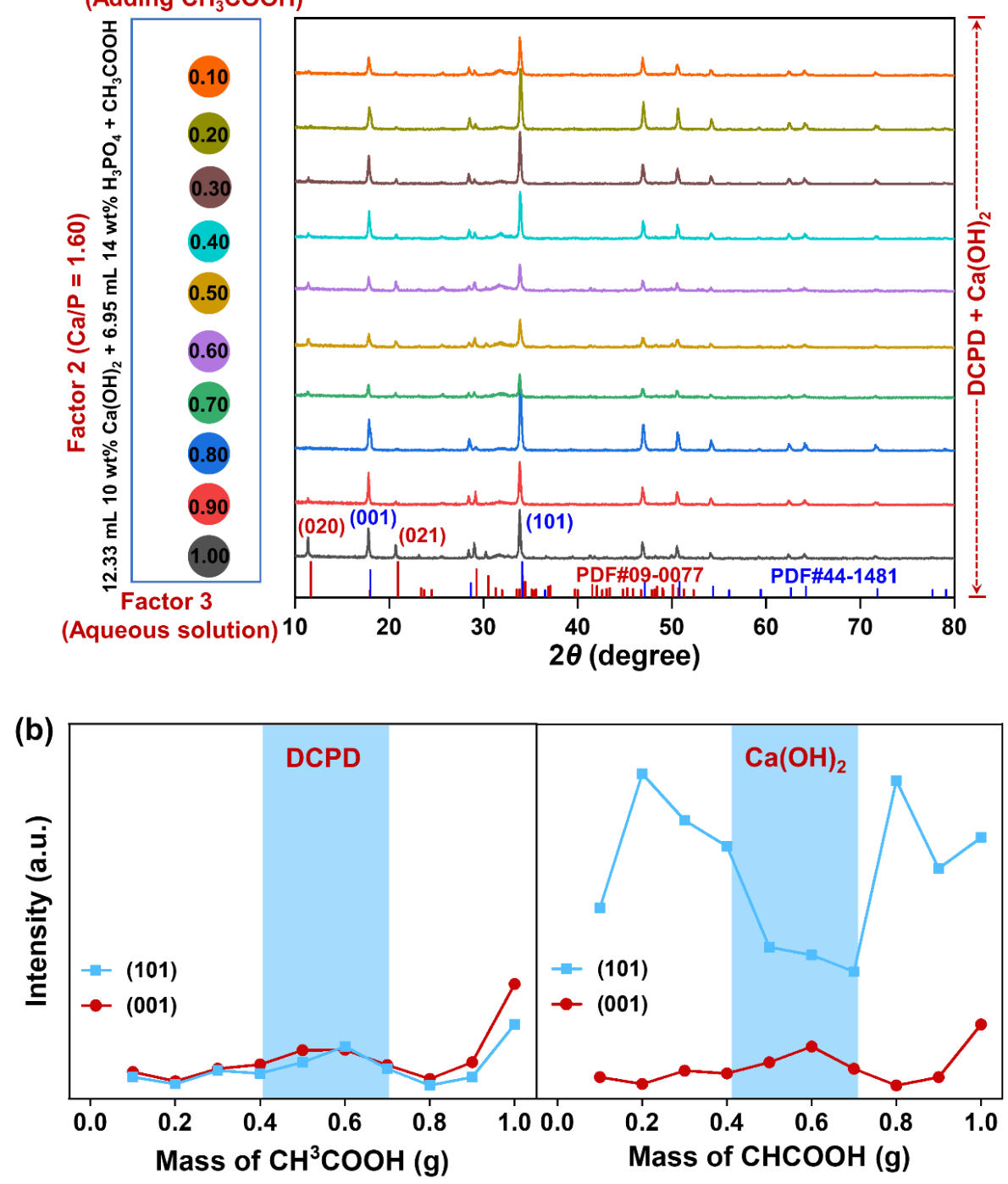

Figure 11. (a) The preparation process and XRD spectrum of as-prepared samples by high-throughput experimentations equipment, (b) intensity of characteristic peaks such as (020) and (021) surfaces of DCPD, (001) and (101) surfaces of $\mathrm{Ca}(\mathrm{OH})_{2}$, respectively. 


\section{Conclusion}

In this work, we have systematically investigated the influence of adding LAC, changing the values of $\mathrm{Ca} / \mathrm{P}$ ratio and $\mathrm{pH}$, and introducing different solvent environments on the aggregation and nucleation of $\mathrm{CaP}$. The $\mathrm{pH}$ dependent protonation states of phosphate species and their coordination modes of $\mathrm{Ca}^{2+}$ ions were analyzed through AIMD and MD simulations with different time and spatial scales. The competitive interaction of $\mathrm{LAC}$ with $\mathrm{Ca}^{2+}$ ions of $\mathrm{CaP}$ clusters or on the surfaces of $\mathrm{HA}$ was featured by electrostatic interaction, which was also affected by the intermolecular hydrogen bonding between LAC and phosphate. With the addition of LAC in neutral and alkaline solutions, those competitive interactions from the oxygen-containing groups led to a decrease of aggregation rate of forming $\mathrm{CaP}$ clusters. The presence of longer oligomer, $\mathrm{LAC}_{8}$, had little effect on the $\mathrm{CaP}$ clustering because of the relatively weak binding ability between $\mathrm{Ca}^{2+}$ ions and $\mathrm{LAC}_{8}$. The predicted inhibition of nucleation process of $\mathrm{CaP}$ was supported by our experiments which indicated that the UV-Vis absorbance values of CaP samples decreased with addition of LAC at the physiological $\mathrm{pH}$ value of 7.4. The charge redistribution at the outmost surface of $\mathrm{CaP}$ cluster was also observed in the presence of LAC, since the exposed groups at outsurface are negatively charged phosphate species instead of $\mathrm{Ca}^{2+}$ ions at the original $\mathrm{CaP}$ surface. The prepared $\mathrm{CaP}$ samples with different $\mathrm{Ca} / \mathrm{P}$ ratios $(1.50,1.67$ and 2.00$)$ showed negative zeta potential values at $\mathrm{pH} \approx 7.4$. The relationship between the zeta potentials of various nano clusters and their biological functions (such as osseointegration, apatite nucleation, and inhibition of tumor cell proliferation) was discussed. The final precipitation was found to be DCPD by XRD. Understand of the influence of interfacial interactions of LAC and other factors such as $\mathrm{pH}$ values and $\mathrm{Ca} / \mathrm{P}$ ratios on the early stage of nucleation process of $\mathrm{CaP}$ is useful to guide the rational design of potential antitumor or tissue regeneration materials. 


\section{Acknowledgments}

This work was supported by the National Key Research and Development Program of China (2017YFB0702601, 2017YFB0702602), the National Natural Science Foundation of China (grant nos. 21873045, 22033004, 21773112). We are grateful to the High Performance Computing Centre of Nanjing University for providing the IBM Blade cluster system.

\section{Author Contributions}

J.M. and H.C. designed all the computations. C.L., L,G., and X.G conceived the experiments and performed characterizations (XRD, TEM, UV-Vis and Zeta potential). M.M., Z.L., J.L., H.C., and X.Z. guided the high-throughput experimentations. J.H., H.D., Q.Z., Y.G., and Z.L provided the data analysis scripts. All authors contributed to discussing the results as well as the writing and revising of the manuscript.

\section{Notes}

The authors declare no competing financial interest.

\section{References}

(1) Nudelman, F.; Sommerdijk, N. A. Biomineralization as an inspiration for materials chemistry. Angew. Chem. Int. Ed. 2012, 51 (27), 6582-6596.

(2) Erdemir, D.; Lee, A. Y.; Myerson, A. S. Nucleation of crystals from solution: classical and two-step models. Acc. Chem. Res. 2009, 42 (5), 621-629.

(3) Habraken, W. J.; Tao, J.; Brylka, L. J.; Friedrich, H.; Bertinetti, L.; Schenk, A. S.; Verch, A.; Dmitrovic, V.; Bomans, P. H.; Frederik, P. M. Ion-association complexes unite classical and nonclassical theories for the biomimetic nucleation of calcium phosphate. Nat. Commun. 2013, 4 (1), 1-12.

(4) Mancardi, G.; Terranova, U.; de Leeuw, N. H. Calcium phosphate prenucleation complexes in water by means of ab initio molecular dynamics simulations. Cryst. Growth Des. 2016, 16 (6), 3353-3358. 
(5) Garcia, N. A.; Malini, R. I.; Freeman, C. L.; Demichelis, R.; Raiteri, P.; Sommerdijk, N. A.; Harding, J. H.; Gale, J. D. Simulation of calcium phosphate prenucleation clusters in aqueous solution: association beyond ion pairing. Cryst. Growth Des. 2019, 19 (11), 6422-6430.

(6) Malini, R. I.; Freeman, C.; Harding, J. Interaction of stable aggregates drives the precipitation of calcium phosphate in supersaturated solutions. CrystEngComm 2019, 21 (42), 6354-6364.

(7) Dorozhkin, S. V. Amorphous calcium (ortho) phosphates. Acta. Biomater. 2010, 6 (12), 4457-4475.

(8) Xie, B.; Halter, T. J.; Borah, B. M.; Nancollas, G. H. Tracking amorphous precursor formation and transformation during induction stages of nucleation. Cryst. Growth Des. 2014, 14 (4), 1659-1665.

(9) Mancardi, G.; Tamargo, C. E. H.; Di Tommaso, D.; De Leeuw, N. H. Detection of Posner's clusters during calcium phosphate nucleation: a molecular dynamics study. J. Mater. Chem. B 2017, 5 (35), $7274-$ 7284.

(10) Habraken, W.; Habibovic, P.; Epple, M.; Bohner, M. Calcium phosphates in biomedical applications: materials for the future? Mater. Today 2016, 19 (2), 69-87.

(11) Meena, R.; Kesari, K. K.; Rani, M.; Paulraj, R. Effects of hydroxyapatite nanoparticles on proliferation and apoptosis of human breast cancer cells (MCF-7). J. Nanopart. Res. 2012, 14 (2), 712.

(12) Sun, Y.; Chen, Y.; Ma, X.; Yuan, Y.; Liu, C.; Kohn, J.; Qian, J. Mitochondria-targeted hydroxyapatite nanoparticles for selective growth inhibition of lung cancer in vitro and in vivo. ACS. Appl. Mater. Inter. 2016, 8 (39), 25680-25690.

(13) Cui, X.; Liang, T.; Liu, C.; Yuan, Y.; Qian, J. Correlation of particle properties with cytotoxicity and cellular uptake of hydroxyapatite nanoparticles in human gastric cancer cells. Mat. Sci. Eng. C 2016, $67,453-460$.

(14) Wu, H.; Li, Z.; Tang, J.; Yang, X.; Zhou, Y.; Guo, B.; Wang, L.; Zhu, X.; Tu, C.; Zhang, X. The in vitro and in vivo anti-melanoma effects of hydroxyapatite nanoparticles: influences of material factors. Int. J. Nanomed. 2019, 14, 1177-1191.

(15) Chu, S.-H.; Feng, D.-F.; Ma, Y.-B.; Li, Z.-Q. Hydroxyapatite nanoparticles inhibit the growth of human glioma cells in vitro and in vivo. Int. J. Nanomed. 2012, 7, 3659-3666.

(16) Khalifehzadeh, R.; Arami, H. Biodegradable calcium phosphate nanoparticles for cancer therapy. Adv. Colloid Interface Sci. 2020, 279, 102157.

(17) Lin, C.-C.; Fu, S.-J.; Lin, Y.-C.; Yang, I.-K.; Gu, Y. Chitosan-coated electrospun PLA fibers for rapid mineralization of calcium phosphate. Int. J. Biol. Macromol. 2014, 68, 39-47.

(18) Guo, Y.; Lan, J.; Zhang, C.; Cao, M.; Cai, Q.; Yang, X. Mineralization on polylactide/gelatin composite nanofibers using simulated body fluid containing amino acid. App. Surf. Sci. 2015, 349, 538548 .

(19) Park, K. H.; Kim, S.-J.; Jeong, Y.-H.; Moon, H.-J.; Song, H.-J.; Park, Y.-J. Fabrication and biological properties of calcium phosphate/chitosan composite coating on titanium in modified SBF. Mat. Sci. Eng. C 2018, 90, 113-118.

(20) Wang, J.; Nor Hidayah, Z.; Razak, S. I. A.; Kadir, M. R. A.; Nayan, N. H. M.; Li, Y.; Amin, K. A. M. Surface entrapment of chitosan on 3D printed polylactic acid scaffold and its biomimetic growth of hydroxyapatite. Compos. Interface. 2019, 26 (5), 465-478.

(21) Wang, D.; Jang, J.; Kim, K.; Kim, J.; Park, C. B. "Tree to Bone": Lignin/Polycaprolactone Nanofibers for Hydroxyapatite Biomineralization. Biomacromolecules 2019, 20 (7), 2684-2693.

(22) Fragal, E. H.; Cellet, T. S.; Fragal, V. H.; Witt, M. A.; Companhoni, M. V.; Ueda-Nakamura, T.; Silva, R.; Rubira, A. F. Biomimetic nanocomposite based on hydroxyapatite mineralization over 
chemically modified cellulose nanowhiskers: An active platform for osteoblast proliferation. Int. J. Biol. Macromol. 2019, 125, 133-142.

(23) Murari, G.; Bock, N.; Zhou, H.; Yang, L.; Liew, T.; Fox, K.; Tran, P. A. Effects of polydopamine coatings on nucleation modes of surface mineralization from simulated body fluid. Sci. Rep. 2020, 10 (1), 1-9.

(24) Salama, A.; Hesemann, P. Synthesis and characterization of N-guanidinium chitosan/silica ionic hybrids as templates for calcium phosphate mineralization. Int. J. Biol. Macromol. 2020, 147, 276-283.

(25) Xiao, Y.; Yang, Y.; Li, J.; Ma, Y.; Wang, H.; Wang, L.; Huang, Y.; Zhang, P.; Zou, Q.; Lai, X. Porous composite calcium citrate/polylactic acid materials with high mineralization activity and biodegradability for bone repair tissue engineering. Int. J. Poly. Mater. Polym.Biomater 2020, 70 (7): 507-520.

(26) Wei, W.; Zhang, X.; Cui, J.; Wei, Z. Interaction between low molecular weight organic acids and hydroxyapatite with different degrees of crystallinity. Colloid Surf. A: Physocochem. Eng. Aspects 2011, $392(1), 67-75$.

(27) Sadat-Shojai, M.; Khorasani, M.-T.; Jamshidi, A. Hydrothermal processing of hydroxyapatite nanoparticles-A Taguchi experimental design approach. J. Cryst. Growth 2012, 361, 73-84.

(28) Zou, X.; Zhao, Y.; Zhang, Z. Preparation of hydroxyapatite nanostructures with different morphologies and adsorption behavior on seven heavy metals ions. J. Contam. Hydrol. 2019, 226, 103538.

(29) Villanueva, A.; Canete, M.; Roca, A. G.; Calero, M.; Veintemillas-Verdaguer, S.; Serna, C. J.; del Puerto Morales, M.; Miranda, R. The influence of surface functionalization on the enhanced internalization of magnetic nanoparticles in cancer cells. Nanotechnology 2009, 20 (11), 115103.

(30) Sakthivel, N.; Socrates, R.; Shanthini, G.; Rajaram, A.; Kalkura, S. N. Silver ion impregnated composite biomaterial optimally prepared using zeta potential measurements. Mat. Sci. Eng. C 2015, 47, 222-229.

(31) Fahami, A.; Beall, G. W.; Betancourt, T. Synthesis, bioactivity and zeta potential investigations of chlorine and fluorine substituted hydroxyapatite. Mat. Sci. Eng. C 2016, 59, 78-85.

(32) Skwarek, E.; Janusz, W.; Sternik, D. Adsorption of citrate ions on hydroxyapatite synthetized by various methods. J. Radioanal. Nucl. Chem. 2014, 299 (3), 2027-2036.

(33) Skwarek, E. Thermal analysis of hydroxyapatite with adsorbed oxalic acid. J. Therm. Anal. Calorim. 2015, 122 (1), 33-45.

(34) Janusz, W.; Skwarek, E. Adsorption of malic acid at the hydroxyapatite/aqueous $\mathrm{NaCl}$ solution interface. Appl. Nanosci. 2021, 1-9.

(35) Kim, H.; Mondal, S.; Jang, B.; Manivasagan, P.; Moorthy, M. S.; Oh, J. Biomimetic synthesis of metal-hydroxyapatite (Au-HAp, Ag-HAp, Au-Ag-HAp): Structural analysis, spectroscopic characterization and biomedical application. Ceram. Int. 2018, 44 (16), 20490-20500.

(36) Wang, X.; Hu, Y.; Mo, J.; Zhang, J.; Wang, Z.; Wei, W.; Li, H.; Xu, Y.; Ma, J.; Zhao, J. Arsenene: a potential therapeutic agent for acute promyelocytic leukaemia cells by acting on nuclear proteins. Angew. Chem. Int. Ed. 2020, 59 (13), 5151-5158.

(37) Lukasheva, N.; Tolmachev, D. Cellulose nanofibrils and mechanism of their mineralization in biomimetic synthesis of hydroxyapatite/native bacterial cellulose nanocomposites: Molecular dynamics simulations. Langmuir 2016, 32 (1), 125-134. 
(38) Ma, J. A molecular dynamics study on the nucleation of calcium phosphate regulated by collagen. J. Mater. Sci. 2014, 49 (8), 3099-3106.

(39) Xue, Z.; Yang, M.; Xu, D. Nucleation of biomimetic hydroxyapatite nanoparticles on the surface of type I collagen: molecular dynamics investigations. J. Phys. Chem. C 2019, 123 (4), 2533-2543.

(40) Tan, X.; Xue, Z.; Zhu, H.; Wang, X.; Xu, D. How charged amino acids regulate nucleation of biomimetic hydroxyapatite nanoparticles on the surface of collagen mimetic peptides: molecular dynamics and free energy investigations. Cryst. Growth Des. 2020, 20 (7), 4561-4572.

(41) Almora-Barrios, N.; De Leeuw, N. H. Molecular dynamics simulation of the early stages of nucleation of hydroxyapatite at a collagen template. Cryst. Growth Des. 2012, 12 (2), 756-763.

(42) Lou, Z.; Zeng, Q.; Chu, X.; Yang, F.; He, D.; Yang, M.; Xiang, M.; Zhang, X.; Fan, H. Firstprinciples study of the adsorption of lysine on hydroxyapatite (100) surface. Appl. Surf. Sci. 2012, 258 (11), 4911-4916.

(43) Gu, H.; Xue, Z.; Wang, M.; Yang, M.; Wang, K.; Xu, D. Effect of hydroxyapatite surface on BMP2 biological properties by docking and molecular simulation approaches. J. Phys. Chem. B 2019, 123 (15), 3372-3382.

(44) Zhu, C.; Zhou, X.; Liu, Z.; Chen, H.; Wu, H.; Yang, X.; Zhu, X.; Ma, J.; Dong, H. The morphology of hydroxyapatite nanoparticles regulates cargo recognition in clathrin-mediated endocytosis. Front. Mol. Biosci. 2021, 8, 627015 .

(45) Golda-Cepa, M.; Riedlová, K.; Kulig, W.; Cwiklik, L.; Kotarba, A. Functionalization of the parylene c surface enhances the nucleation of calcium phosphate: combined experimental and molecular dynamics simulations approach. ACS. Appl. Mater. Inter. 2020, 12 (11), 12426-12435.

(46) Hamad, K.; Kaseem, M.; Yang, H.; Deri, F.; Ko, Y. Properties and medical applications of polylactic acid: A review. Express Polym. Lett. 2015, 9 (5), 435-455.

(47) Colegio, O. R.; Chu, N.-Q.; Szabo, A. L.; Chu, T.; Rhebergen, A. M.; Jairam, V.; Cyrus, N.; Brokowski, C. E.; Eisenbarth, S. C.; Phillips, G. M. Functional polarization of tumour-associated macrophages by tumour-derived lactic acid. Nature 2014, 513 (7519), 559-563.

(48) Marchiq, I.; Pouysségur, J. Hypoxia, cancer metabolism and the therapeutic benefit of targeting lactate/H+ $\mathrm{H}^{+}$symporters. J. Mol. Med. 2016, 94 (2), 155-171.

(49) Narendranath, N.; Thomas, K.; Ingledew, W. Effects of acetic acid and lactic acid on the growth of Saccharomyces cerevisiae in a minimal medium. J. Ind. Microbiol. Biotechnol. 2001, 26 (3), 171-177.

(50) Shevlin, M. Practical high-throughput experimentation for chemists. ACS Med. Chem. Lett. 2017, 8 (6), 601-607.

(51) Gaussian 16, R. A., Frisch, M. J.; Trucks, G. W.; Schlegel, H. B.; Scuseria, G. E.; Robb, M. A.; Cheeseman, J. R.; Scalmani, G.; Barone, V.; Petersson, G. A.; Nakatsuji, H.; Li, X.; Caricato, M.; Marenich, A. V.; Bloino, J.; Janesko, B. G.; Gomperts, R.; Mennucci, B.; Hratchian, H. P.; Ortiz, J. V.; Izmaylov, A. F.; Sonnenberg, J. L.; Williams-Young, D.; Ding, F.; Lipparini, F.; Egidi, F.; Goings, J.; Peng, B.; Petrone, A.; Henderson, T.; Ranasinghe, D.; Zakrzewski, V. G.; Gao, J.; Rega, N.; Zheng, G.; Liang, W.; Hada, M.; Ehara, M.; Toyota, K.; Fukuda, R.; Hasegawa, J.; Ishida, M.; Nakajima, T.; Honda, Y.; Kitao, O.; Nakai, H.; Vreven, T.; Throssell, K.; Montgomery, J. A., Jr.; Peralta, J. E.; Ogliaro, F.; Bearpark, M. J.; Heyd, J. J.; Brothers, E. N.; Kudin, K. N.; Staroverov, V. N.; Keith, T. A.; Kobayashi, R.; Normand, J.; Raghavachari, K.; Rendell, A. P.; Burant, J. C.; Iyengar, S. S.; Tomasi, J.; Cossi, M.; Millam, J. M.; Klene, M.; Adamo, C.; Cammi, R.; Ochterski, J. W.; Martin, R. L.; Morokuma, K.; Farkas, O.; Foresman, J. B.; Fox, D. J. Gaussian, Inc., Wallingford CT, 2016. 
(52) Kresse, G.; Furthmüller, J. Efficient iterative schemes for ab initio total-energy calculations using a plane-wave basis set. Phys. Rev. B 1996, 54 (16), 11169-11186.

(53) Kresse, G.; Furthmüller, J. Efficiency of ab-initio total energy calculations for metals and semiconductors using a plane-wave basis set. Comp. Mater. Sci. 1996, 6 (1), 15-50.

(54) Grimme, S.; Antony, J.; Ehrlich, S.; Krieg, H. A consistent and accurate ab initio parametrization of density functional dispersion correction (DFT-D) for the 94 elements H-Pu. J. Chem. Phys. 2010, 132 (15), 154104.

(55) Tang, W.; Sanville, E.; Henkelman, G. A grid-based Bader analysis algorithm without lattice bias. J. Phys.: Condens. Matter. 2009, 21 (8), 084204.

(56) D.A. Case, R. M. B., D.S. Cerutti, T.E. Cheatham, III, T.A. Darden, R.E. Duke, T.J. Giese, H. Gohlke,A.W. Goetz, N. Homeyer, S. Izadi, P. Janowski, J. Kaus, A. Kovalenko, T.S. Lee, S. LeGrand, P. Li, C.Lin, T. Luchko, R. Luo, B. Madej, D. Mermelstein, K.M. Merz, G. Monard, H. Nguyen, H.T. Nguyen, I.Omelyan, A. Onufriev, D.R. Roe, A. Roitberg, C. Sagui, C.L. Simmerling, W.M. BotelloSmith, J. Swails,R.C. Walker, J. Wang, R.M. Wolf, X. Wu, L. Xiao and P.A. Kollman (2016), AMBER 2016, University of California, San Francisco.

(57) Siparsky, G. L.; Voorhees, K. J.; Miao, F. Hydrolysis of polylactic acid (PLA) and polycaprolactone (PCL) in aqueous acetonitrile solutions: autocatalysis. J. Environ. Polym. Degr. 1998, 6 (1), 31-41.

(58) Kim, M. S.; Choi, Y.; Fernandez, N. J.; Sponza, A. D.; Navarro, A. E. Biosorption of phosphate by novel biomaterials: an asset against eutrophication of water resources. Biotechnology 2014, 8, 25-34.

(59) Damar, S.; Balaban, M. O. Review of dense phase $\mathrm{CO}_{2}$ technology: microbial and enzyme inactivation, and effects on food quality. J. Food Sci. 2006, 71 (1), R1-R11.

(60) Joshi, R. Charge transfer reactions from tryptophan and tyrosine to sulfur-centered dimer radical cation in aqueous-sulfuric acid medium: a pulse radiolysis study. J. Phys. Org. Chem. 2016, 29 (6), 281 287.

(61) Wu, X.; Brooks, B. R. Self-guided Langevin dynamics simulation method. Chem. Phys. Lett. 2003, 381 (3-4), 512-518.

(62) Baker, N. A.; Sept, D.; Joseph, S.; Holst, M. J.; McCammon, J. A. Electrostatics of nanosystems: application to microtubules and the ribosome. Proc. Natl. Acad. Sci. USA. 2001, 98 (18), 10037-10041. (63) Kühne, T. D.; Iannuzzi, M.; Del Ben, M.; Rybkin, V. V.; Seewald, P.; Stein, F.; Laino, T.; Khaliullin, R. Z.; Schütt, O.; Schiffmann, F. CP2K: An electronic structure and molecular dynamics software package-Quickstep: Efficient and accurate electronic structure calculations. J. Chem. Phys. 2020, 152 (19), 194103.

(64) VandeVondele, J.; Hutter, J. Gaussian basis sets for accurate calculations on molecular systems in gas and condensed phases. J. Chem. Phys. 2007, 127 (11), 114105.

(65) Martínez, L.; Andrade, R.; Birgin, E. G.; Martínez, J. M. PACKMOL: a package for building initial configurations for molecular dynamics simulations. J. Comput. Chem. 2009, 30 (13), 2157-2164.

(66) Moya-Hernández, R.; Rueda-Jackson, J. C.; Havel, J.; Ramírez, M. T.; Vázquez, G. A.; RojasHernández, A. Statistical study of distribution diagrams for two-component systems: relationships of means and variances of the discrete variable distributions with average ligand number and intrinsic buffer capacity. J. Chem. Educ. 2002, 79 (3), 389-392.

(67) Eanes, E.; Meyer, J. The maturation of crystalline calcium phosphates in aqueous suspensions at physiologic pH. Calcif. Tissue Res. 1977, 23 (1), 259-269. 
(68) De Maeyer, E. A.; Verbeeck, R. M.; Vercruysse, C. W. Conversion of octacalcium phosphate in calcium phosphate cements. J. Biomed. Mater. Res. 2000, 52 (1), 95-106.

(69) Tang, E.; Di Tommaso, D.; de Leeuw, N. H. Accuracy of the microsolvation-continuum approach in computing the $\mathrm{pK}_{\mathrm{a}}$ and the free energies of formation of phosphate species in aqueous solution. Phys. Chem. Chem. Phys. 2010, 12 (41), 13804-13815.

(70) Zhang, H.; Darvell, B. W. Morphology and structural characteristics of hydroxyapatite whiskers: effect of the initial Ca concentration, Ca/P ratio and pH. Acta biomater. 2011, 7 (7), 2960-2968.

(71) Chiatti, F.; Delle Piane, M.; Ugliengo, P.; Corno, M. Water at hydroxyapatite surfaces: the effect of coverage and surface termination as investigated by all-electron B3LYP-D* simulations. Theor. Chem. Acc. 2016, 135 (3), 54.

(72) Almora-Barrios, N.; Austen, K. F.; de Leeuw, N. H. Density functional theory study of the binding of glycine, proline, and hydroxyproline to the hydroxyapatite (0001) and (0110) surfaces. Langmuir 2009, 25 (9), 5018-5025.

(73) Corno, M.; Rimola, A.; Bolis, V.; Ugliengo, P. Hydroxyapatite as a key biomaterial: quantummechanical simulation of its surfaces in interaction with biomolecules. Phys. Chem. Chem. Phys. 2010, 12 (24), 6309-6329.

(74) Zhang, Q.; Jiang, Y.; Gou, B.-D.; Huang, J.; Gao, Y.-X.; Zhao, J.-T.; Zheng, L.; Zhao, Y.-D.; Zhang, T.-L.; Wang, K. In situ detection of calcium phosphate clusters in solution and wet amorphous phase by synchrotron X-ray absorption near-edge spectroscopy at calcium K-edge. Cryst. Growth Des. 2015, 15 (5), 2204-2210.

(75) Yin, X.; Stott, M. J. Biological calcium phosphates and Posner's cluster. J. Chem. Phys. 2003, 118 (8), 3717-3723.

(76) Patil, S.; Sandberg, A.; Heckert, E.; Self, W.; Seal, S. Protein adsorption and cellular uptake of cerium oxide nanoparticles as a function of zeta potential. Biomaterials 2007, 28 (31), 4600-4607.

(77) Lu, X.; Leng, Y. Theoretical analysis of calcium phosphate precipitation in simulated body fluid. Biomaterials 2005, 26 (10), 1097-1108.

(78) Wong, A.-C.; Czernuszka, J. Transformation behaviour of calcium phosphate 1. Theory and modelling. Colloid Surf. A: Physocochem. Eng. Aspects 1993, 78, 245-253.

(79) Xin, R.; Leng, Y.; Chen, J.; Zhang, Q. A comparative study of calcium phosphate formation on bioceramics in vitro and in vivo. Biomaterials 2005, 26 (33), 6477-6486.

(80) Tan, S.; Chen, S.; Wang, Y.; Wu, F.; Shi, Y.; Wang, J.; Du, Y.; Zhang, S. Enhanced effect of nanomonetite hydrosol on dentin remineralization and tubule occlusion. Dent. Mater. 2020, 36 (6), 816-825. 